\title{
A Survey of Robot-Assisted Language Learning (RALL)
}

\author{
NATASHA RANDALL, School of Informatics, Computer Science, and Engineering, Indiana University
}

\begin{abstract}
Robot-assisted language learning (RALL) is becoming a more commonly studied area of human-robot interaction (HRI). This research draws on theories and methods from many different fields, with researchers utilizing different instructional methods, robots, and populations to evaluate the effectiveness of RALL. This survey details the characteristics of robots used-form, voice, immediacy, non-verbal cues, and personalizationalong with study implementations, discussing research findings. It also analyzes robot effectiveness. While research clearly shows that robots can support native and foreign language acquisition, it has been unclear what benefits robots provide over computer-assisted language learning. This survey examines the results of relevant studies from 2004 (RALL's inception) to 2017. Results suggest that robots may be uniquely suited to aid in language production, with apparent benefits in comparison to other technology. As well, research consistently indicates that robots provide unique advantages in increasing learning motivation and in-task engagement, and decreasing anxiety, though long-term benefits are uncertain. Throughout this survey, future areas of exploration are suggested, with the hope that answers to these questions will allow for more robust design and implementation guidelines in RALL.
\end{abstract}

CCS Concepts: $\bullet$ Human-centered computing $\rightarrow$ Interaction paradigms; Interaction design; $\bullet$ Applied computing $\rightarrow$ Computer-assisted instruction; • Computer systems organization $\rightarrow$ Robotics;

Additional Key Words and Phrases: Robot-assisted language learning, RALL, robot-assisted learning, RAL, r-learning, intelligent tutoring system, human-robot interaction, social robotics, educational service robots

\section{ACM Reference format:}

Natasha Randall. 2019. A Survey of Robot-Assisted Language Learning (RALL). ACM Trans. Hum.-Robot Interact. 9, 1, Article 7 (December 2019), 36 pages.

https://doi.org/10.1145/3345506

\section{INTRODUCTION}

Using robots in education is becoming increasingly popular. One area that has seen recent growth is the application of robots to assist in language acquisition. This is likely attributable to many factors, including advances in speech recognition and text-to-speech (TTS) capabilities, increased development of sophisticated commercial and research robots, and an enhanced understanding of how language skills contribute to immediate and long-term success. In early development specifically, research shows that children's language ability is a predictor of later academic success [2, $26,105]$. Furthermore, learning a second language confers advantages whether it is learnt as a child or an adult [12]. Bilingualism has been linked to superior executive functioning, higher IQ scores, and better job and economic opportunities $[1,12,88]$. It is also thought to offer a protective effect against dementia [15]. Foreign language education is also becoming increasingly important

Author's address: N. Randall, Indiana University, School of Informatics, Computing, and Engineering, 919 E 10th St., Bloomington, IN 47408; email: nprandal@iu.edu.

Permission to make digital or hard copies of all or part of this work for personal or classroom use is granted without fee provided that copies are not made or distributed for profit or commercial advantage and that copies bear this notice and the full citation on the first page. Copyrights for components of this work owned by others than the author(s) must be honored. Abstracting with credit is permitted. To copy otherwise, or republish, to post on servers or to redistribute to lists, requires prior specific permission and/or a fee. Request permissions from permissions@acm.org.

(C) 2019 Copyright held by the owner/author(s). Publication rights licensed to ACM.

2573-9522/2019/12-ART7

https://doi.org/10.1145/3345506 
due to globalization, which requires cross-cultural interaction for fostering business and personal connections.

Robot-assisted language learning (RALL) is defined as the use of robots to teach people language expression or comprehension skills-such as speaking, writing, reading, or listening. This includes native and non-native language instruction in both spoken and non-verbal languages, such as sign language. RALL is a subdomain of robot-assisted learning (RAL or r-learning), which also leverages educational robots for teaching purposes. They have much in common, but in addressing a unique problem space, RALL offers its own pedagogical grounding and implementation challenges (see Sections 6.4 and 7.1-Instructional Methods and Challenges). However, both fields can mutually inform each other.

Robot-assisted learning is a niche area in social robotics and human-robot interaction (HRI). Specifically, while they overlap in some aims such as the importance of acceptability by users, the desire for interpretable and safe interactions, and relationship development, robots in teaching or tutoring roles are also to be judged by their efficacy in information transfer. Therefore, there need to be domain-specific considerations when designing their form, speech, and behaviors. Still, RALL incorporates findings from HRI more generally and can use previous work to guide future areas of study. Findings in RALL can also be applied to HRI more broadly-such as the novelty effect, where strong support is typically cited as Kanda 2004 et al., the first paper published on RALL.

Social robots seem extremely appropriate for use in language learning as it is an inherently social endeavor [41, 109]. It is "not just about exposure to words-it is also... about communicating meaning and having a social interaction that happens to use words to communicate" [58:643]. This potentially makes robots especially apt communication partners compared to other technologies, as embodiment enhances ascriptions of an agent as a social partner [49, 104]. Integrating insights from References $[8,20,58,73]$ and others, several other advantages of using robots include: (1) intelligence-endowment with sensors that allow communication and interaction with the environment; (2) anthropomorphism-communication in ways that leverage how people naturally interact, such that verbal and non-verbal cues can be easily interpreted; (3) accessibility-ability to be used by people who may not normally have access to instructors, such as those who live in remote areas, as well as those who desire or require additional practice, such as in home or classroom environments; (4) versatility-possible solitary or group use, or use with a caregiver or teacher; (5) customization-ability to be personalized to both the individual and task; (6) updatabilitypotential addition of new content and intelligence; and (7) repeatability-handling repetitive tasks without fatigue, allowing for repeated practice. Additionally, they tend to lower students' anxiety and increase their motivation to learn [7].

How has research aligned with the intuition that social robots are well suited for use in language learning? In short, robots can in fact teach people language, though results on their ability to do so relative to other technology is mixed. As robots in RALL are generally not intended to replace human instructors, only to supplement them, affordances conferred by their embodiment mean they are often contrasted with 2D technology such as computers, tablets, and virtual agents. Compared with these technologies, for instance, there is some support that robots offer unique advantages in helping students with language production and in-task engagement. As well, they seem to have a positive effect on learners' confidence, anxiety, and motivation when used in addition to teacheronly instruction. They do not seem to confer any unique advantages in vocabulary learning, at least not in the short-term. However, more research needs to be conducted in this emerging field to determine the full scope of benefits provided by using robots.

The impetus for this survey is to detail what we know about using robots in language learning. It is far too easy to find literature that supports one's intuitive assumptions, even though 
contradicting work also exists (and may be more compelling). As there is now enough work to begin integrating insights from multiple studies, this review serves as a source of what can be claimed with apparent confidence and which open questions still exist. This is also meant to serve as a concise, yet comprehensive, picture of the field. Specifically, it aims to summarize the results obtained in previous research and the robots used to obtain them, as well as highlight study information that allows more interpretability of findings. The exact topics discussed were determined via a bottom-up approach, by allowing topics to naturally emerge from included articles. This included iterative thematic coding, where the first pass through the articles was meant to identify common themes, and the second served to classify each paper into these themes, if applicable. While a contemporaneous review article presents research on robots in education [14], the current survey's focus on robots for language learning allows more in-depth presentation of findings and suggestions in this area, which are sometimes different than when considering education broadly, and also presents qualitative results in addition to quantitative results. Additionally, although a short overview on RALL is available [52], the current survey is more systematic in its approach, more comprehensive in its research inclusion, and offers a more complete set of findings and caveats when interpreting previous work.

This article begins by outlining previous research surrounding the characteristics of robots in RALL. It then examines the results of using robots in different areas of language development as well as their effects in altering learners' affective states (e.g., motivation and anxiety). It then provides more information about the composition of the studies to further help interpret results (framing the research) and discusses domain-specific challenges. For studies with results on learning or affective changes, details such as age and number of participants, study length, and findings can be found in Tables 2 and 3 of the Appendix, which are organized by results (e.g., vocabulary, motivation). Throughout this survey, attention is drawn to gaps in knowledge and general recommendations are made of where this subfield should head.

\section{SURVEY PROTOCOL}

Papers included in this literature review were located by querying Google Scholar using the search terms "robot assisted language learning," "robot language learning," and "robot tutor language." Google Scholar was chosen as it includes publications from varied research databases, including IEEE Xplore and the ACM Digital Library. It was also thought to be the most inclusive as RALL is an interdisciplinary field, with publications occurring in numerous journals. Additionally, a secondary search was performed by reviewing the references of all relevant papers. Finally, conference and journal publications that appeared at least three times among collected articles were searched individually for papers. This included the International Conference on Advanced Learning Technologies, the International Conference on Human-Robot Interaction, the International Conference on Social Robotics, the International Symposium on Robot and Human Interactive Communication (RO-MAN), the fournal of Educational Technology \& Society, and the fournal of Social Robotics. Transactions on Human-Robot Interaction was also searched due to its status as a top-tier journal in HRI. When two or more papers were found describing the same experiment, the one that provided the most detailed description of the study was chosen for inclusion, unless they provided unique, pertinent information. Papers that only served to summarize past experiments were also excluded. Both quantitative and qualitative results are represented. This survey attempts to include all papers published in December 2017 or prior in the analysis. Results from a total of 79 papers are therefore included. A total of 26 publishers are represented, including IEEE (23 papers), Springer (13 papers), ACM (11 papers), and the International Forum of Educational Technology \& Society (5 papers). 


\section{CHARACTERISTICS OF ROBOTS IN RALL}

Below, the function, form, voice, social role, immediacy behaviors, non-verbal cues, and personalization of robots in RALL are described and results from various studies incorporated, with suggestions for future work made as appropriate. Many of the aforementioned factors allow robots to respond differently than computers, iPads, or onscreen agents, due to their embodiment and perceptions that they are social agents. For instance, even though many forms of technology can be personalized, robots can exhibit personalized non-verbal behaviors in a co-present manner. As well, though onscreen agents can have a social role, robots are often imbued with more human-like qualities that might allow these roles to be more salient. Differences such as these largely explain why robots are hypothesized to be better than other technologies in aiding learning. The themes described below are pervasive throughout the HRI literature, though in RALL optimal characteristics may be different as the metric of success is related to learning.

\subsection{Function}

Robots can be autonomous or teleoperated (e.g., telepresent), or capable of transitioning between both levels of operation [36]. Teleoperated robots are controlled remotely, whereas autonomous robots have programmed behaviors. Some robots (e.g., Robosem) can function either autonomously or by telepresence, depending on the mode. According to Park, Han, Kang, and Shin, this type may be a better choice than robots with only telepresence capabilities if connection to the network is unstable [80]. Both autonomous and teleoperated robots are used often in RALL, and robots with autonomous capabilities are often teleoperated for the purposes of experiments (Wizard of Oz).

Robots of all types can serve several purposes in language learning. They may be used to engage students as their conversational partner (e.g., References [63, 66]), trigger vocabulary or grammar learning (e.g., References [20, 27, 66, 99]), help with pronunciation [66, 106], reading comprehension [42] or writing clarity [47], improve listening skills [42, 50, 66], assess language ability [31, 95], increase positive affect or decrease anxiety [96, 114], or serve as a conversational proxy or avatar for the student [70].

\subsection{Form}

Robots used in RALL (Table 1) can be classified into four groups based on their appearance: anthropomorphic, zoomorphic, mechanomorphic, or cartoon-like (Figure 1). In Table 1, robots are classified as anthropomorphic (A) if they have a human-like torso, arms, legs, and facial features (e.g., NAO) or a realistic human face (e.g., Furhat). Robots are indicated as cartoon-like (C) if they have exaggerated and caricature-like features (e.g., DragonBot). Robots meant to mimic an animal, partly or completely, are designated as zoomorphic (Z) (e.g., iCat). Mechanomorphic (M) is given as a label for robots that have machine-like qualities, such as the ability to transform into multiple shapes, a more industrial appearance, or the lack of distinct facial features (e.g., Scribbler). It should be noted that some robots, such as PET and Robosem, are mixtures of types. Therefore, robots are sometimes classified under multiple categories. As is apparent, anthropomorphic robots are the most often used (NAO being the most widely used robot), followed by cartoon-like robots.

Anthropomorphic robots are often considered superior for supporting language learning. When recommending desired characteristics, Chang, Lee, Chao et al. include the importance of a humanlike appearance, which is postulated to increase student engagement and attribution of the robot as a real conversational partner [20]. However, this opinion is not universally shared. Wu et al. postulated that zoomorphic or cartoon-like robots are likely more appropriate, at least for young children, as they may be less afraid of these forms [114]. This view highlights the influence of form 
Table 1. Robots Used in RALL

\begin{tabular}{|c|c|c|c|}
\hline & Robot & Study & Location(s) \\
\hline 1 & Atti (A) & Kim 2014 [57] & United States \\
\hline 2 & Bioloid $(\mathrm{A}, \mathrm{M})$ & Hong 2016 [42] & Taiwan \\
\hline 3 & DragonBot $(\mathrm{C})$ & $\begin{array}{l}\text { Kory } 2014 \text { [58], Gordon 2015a [32], Gordon 2015b } \\
\text { [31], Westlund 2015a [109], Westlund 2015b [110], } \\
\text { Westlund 2017 [112] }\end{array}$ & United States \\
\hline 4 & EngKey $(C, Z)$ & Lee 2010 [65], Lee 2011 [66], Yun 2011 [119] & South Korea \\
\hline 5 & Furhat (A) & Wedenborn 2015 [108], Lopes 2017 [69] & United States \\
\hline 6 & iCat $(\mathrm{C}, \mathrm{Z})$ & Saerbeck 2010 [87], Mubin 2013 [73] & Netherlands, Unknown \\
\hline 7 & iRobi (C) & Han 2008 [37] & South Korea \\
\hline 8 & iRobiQ (C) & Hyun 2008 [44], Hur 2009 [43], Lee 2015 [64] & South Korea \\
\hline 9 & Kubi (C) & Perlmutter 2016 [81] & United States \\
\hline 10 & LEGO Mindstorm $(\mathrm{A}, \mathrm{M})$ & Mubin 2013 [73] & Unknown \\
\hline 11 & MecWilly (A, M) & Mazzoni 2015 [71] & Italy \\
\hline 12 & Mero (A) & Lee 2010 [65], Lee 2011 [66] & South Korea \\
\hline 13 & MOBiMac (M) & Yorita 2012 [116], Yorita 2013 [115] & Japan \\
\hline 14 & Nabaztag $(\mathrm{C}, \mathrm{Z})$ & Eimler 2010 [27] & Germany \\
\hline 15 & $\mathrm{NAO}(\mathrm{A})$ & $\begin{array}{l}\text { Kose } 2011 \text { [61], Kose } 2012 \text { [62], Tanaka } 2012 \text { [99], } \\
\text { Ertugrul } 2013 \text { [29], Akalin 2013 [3], Akalin, 2014 } \\
\text { [4], Kose } 2014 \text { [59], Alemi 2014a [8], Alemi 2014b } \\
\text { [9], Alemi 2015a [5], Alemi 2015b [7], Kose 2015 } \\
\text { [60], Herberg 2015 [41], Shin 2015 [96], Kennedy } \\
\text { 2016 [54], Alemi 2016 [6], Balkibekov } 2016 \text { [13], } \\
\text { Ishida 2016 [46], Jacq 2016 [47], Alemi } 2017 \text { [10], } \\
\text { Hemminki 2017 [39], Khalifa 2017 [56], Schodde } \\
\text { 2017a [91], Schodde 2017b [92], Vogt 2017a [103], } \\
\text { Vogt 2017b [102] }\end{array}$ & $\begin{array}{l}\text { Finland, Germany, Iran, } \\
\text { Japan, Kazakhstan, } \\
\text { Netherlands, Singapore, } \\
\text { South Korea, } \\
\text { Switzerland, Turkey, } \\
\text { United States }\end{array}$ \\
\hline 16 & $\operatorname{PET}(\mathrm{C}, \mathrm{Z})$ & Wu 2015 [114] & Taiwan \\
\hline 17 & RASA (A) & Zakipour $2016[120]$ & Iran \\
\hline 18 & Robosapien (A, M) & You 2006 [117], Lu 2007 [70], Chang 2010a [20] & Taiwan \\
\hline 19 & Robosem (A, M) & $\begin{array}{l}\text { Park } 2011 \text { [80], Shim } 2012 \text { [95], Shin } 2017 \text { [97], In } \\
2015 \text { [45] }\end{array}$ & South Korea \\
\hline 20 & Robovie II (A, M) & Kanda 2004 [50] & Japan \\
\hline 21 & Robovie R3 (A) & $\begin{array}{l}\text { Tanaka } 2013 \text { [100], Akalin } 2014 \text { [4], Kose } 2015 \text { [60], } \\
\text { Uluer } 2015 \text { [101] }\end{array}$ & Japan, Turkey \\
\hline 22 & Rocky $(\mathrm{C}, \mathrm{Z})$ & Wang 2009 [106], Young 2010 [118] & Taiwan \\
\hline 23 & RUBI-4 $(\mathrm{A}, \mathrm{C})$ & Movellan 2009 [72] & United States \\
\hline 24 & Scribbler $(\mathrm{M})$ & Chen 2009 [22], Chang 2010b [21] & Taiwan \\
\hline 25 & TEGA (C) & Westlund 2015c [111], Gordon 2016 [33] & United States \\
\hline 26 & TIRO (C) & Han 2009 [38] & South Korea \\
\hline 27 & unnamed_1 (C, M) & Kwon 2010 [63] & South Korea \\
\hline 28 & unnamed_2 (A, M) & Chen 2011 [23] & Taiwan \\
\hline 29 & unnamed_3 (C) & Wang 2013 [107] & Taiwan \\
\hline 30 & unnamed_4 (A) & Bae 2017 [11] & South Korea \\
\hline
\end{tabular}

*First author listed above

$\begin{array}{ll}\mathrm{A}=\text { Anthropomorphic } & \mathrm{Z}=\text { Zoomorphic } \\ \mathrm{C}=\text { Cartoon-like } & \mathrm{M}=\text { Mechanomorphic }\end{array}$


1. NAO (Anthropomorphic)

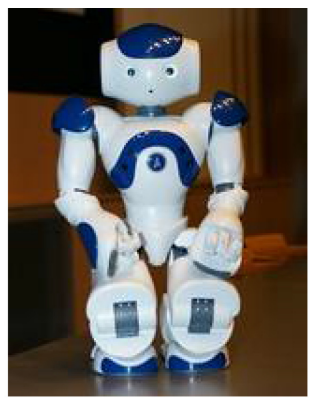

"dsc05109.arw" by derfian is licensed under CC BY-NCSA 2.0

\section{DragonBot (Cartoon-like)}

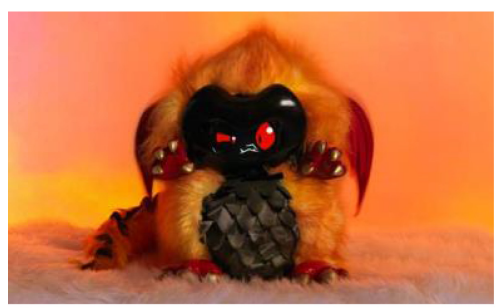

(C) Personal Robots Group

\section{2. iCat (Zoomorphic)}

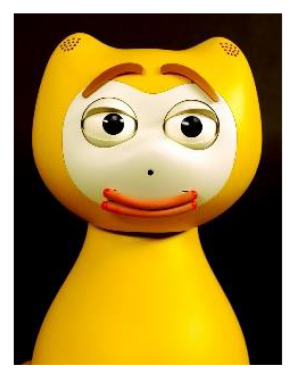

(C) Christoph Bartneck

\section{Scribbler (Mechanomorphic)}

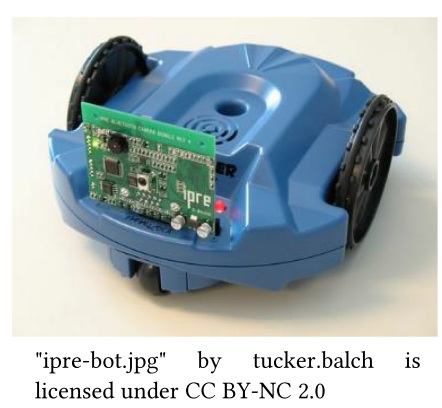

Fig. 1. Examples of Four Appearance Types.

on the affective filter (e.g., the experience of anxiety), and the role of cute and likeable agents in reducing it. It also emphasizes that chosen robots should appeal to the students [114]. There is some support for this view. Previous research "did not find a positive effect of pedagogical agents on motivation or learning on the general level, but demonstrated that likeable agents lead to a higher motivation and increased transfer performance" [27] (summarizing Domagk 2008).

In the one study in RALL that surveyed preferences of robotic form (in Taiwan), it was reported that boys preferred to learn from robots that looked like cartoon or video game characters and that were made out of wood, while girls preferred robots that looked like stuffed animals [118]. Yet, there were methodological limitations to this study, the most obvious being that human was not included as an answer choice. Therefore, we cannot conclude where humanoid would fall on their lists.

When children were surveyed in one study, some expressed displeasure with how the robot looked [66]. This is non-trivial as form, even subtle variations of it, clearly affects perceptions of robots. Osada, Ohnaka, and Sato saw that people ascribe distinct personalities to differently colored Papero robots [76]. Different forms have also been linked with attributions of different social roles. Size can factor into the equation when determining whether a robot is a toy or a social other [59,101]. More research needs to be conducted into preferences in robot form, and if this correlates with increased language learning. Age, gender, and cultural effects should be examined.

There are some insights that can be obtained on this issue by looking at studies done with NAO and Robovie in sign language learning. When testing Turkish sign recognition with videos of NAO 
or Robovie, Köse et al. found that there was no difference in performance between learning with NAO or Robovie [60]. This was true within the three groups for which results were reported: children with beginning sign language experience, children with advanced sign language experience, and adults with no experience [60]. However, when adults were tested using a physical NAO or a physical Robovie, they recognized signs at a much higher rate when Robovie performed them. [59]. Robovie's longer arms, five fingers (as opposed to NAO's three fingers), and larger size may be the cause [60], though it is interesting that no difference was seen with video learning. This suggests that form may have an influence in $3 \mathrm{D}$ interactions that it does not have in $2 \mathrm{D}$. It is worth studying whether exact agent form is more important for learning when the actor is physically present, and relatively less so when in videos.

Additionally, Köse et al. compared subjects' results from learning from Robovie in video format to those with the physically present Robovie [60]. Children with advanced knowledge of sign and adults did equally well in both conditions, but children with beginner's knowledge of sign did significantly better with the embodied Robovie. No effects by gender were seen [60]. By contrast, Chang, Lee, Wang, and Chen found no difference in word learning between eighth-graders using an embodied or virtual Scribbler, but found they reported higher levels of engagement, motivation, and perceived authority with the physical robot [21]. It is important to note, however, that while Köse et al. used an objective measure of learning, Chang et al. relied on self-reports of word learning, making it a less reliable indicator of whether learning actually occurred. The participants in this study were also older than the children in the Kose study. These results allow for many possible interpretations. One is that embodiment may be more important for children in earlier stages of learning, though effects on motivation and other factors may be seen at any age or level.

As these were very short-term studies, it is difficult to conclude how long-term interactions might alter the relationships that were seen. More research needs to be conducted into how form relates to outcomes in the long-term and in studies with larger sample sizes. As well, as Robovie had an advantage over NAO in its physical capacity to perform the signs, studies need to be conducted to inform whether differences in the look of the robots, but not in their capabilities to teach the language, can influence learning.

\subsection{Voice}

A robot may have either a synthetic voice or a pre-recorded voice. The exception is telepresence robots, which allow for the presence of a live speaker; hence, this section will focus on autonomous robots and teleoperated robots with voice capabilities.

The use of synthetic voices is most common in RALL (e.g., References [32, 74, 80]). They are produced by text-to-speech (TTS) software, including Microsoft SDK [117], Festival [73, 74], or the robot's native TTS module. Due to the flexibility in this method, the voices can have different identities (age, gender, language), and there can be considerable variation in the voices produced. This allows the robot to take on the voices of different characters, as sometimes used when telling a story $[20,114,117]$. This also allows purposeful exposure to varied voices and accents $[20,114]$. That said, due to large variations in quality, students are not always satisfied with the voice produced $[66,87]$. Furthermore, poor quality output may result in decreased language comprehension skills [66] and hinder correct prosody [45]. Although not tested, it is plausible that this will also affect pronunciation skills.

An alternative to speech synthesis is to pre-record desired speech. This approach has been taken several times (e.g., References [13, 50,61]). Although not common, this output may be processed after recording, for example by pitch shifting an adult voice to make it sound child-like [111, 112].

Pre-recorded voices are advantageous in that they more readily carry emotion [111]. They may also be preferred for their ability to expose learners to naturalistic speech. As Rosenthal-von der 
Pütten, Strassmann, and Krämer found no difference in the extent to which people mimic a robot's word choice or word order when it uses TTS or pre-recorded voices [85], this may mean that linguistic alignment will occur in other areas of speech as well. In fact, prosody and pause insertion are often aligned to conversational partners, even non-animate partners such as computers and virtual agents $[18,77]$, making the use of TTS potentially problematic in long-term language learning. However, one drawback to using natural speech, besides being more time- and labor-intensive to record, is that native speech is often fast. Kanda, Sato, Saiwaki, and Ishiguro, in reference to their 2004 study, suggested that they saw no significant increase in learning because the robot used a native English speaker's voice, and this may have been too fast and fluent for Japanese children with little prior exposure to the language to understand [51]. The benefits of using natural speech over TTS may be muted in the future, with the use of current and projected AI capabilities, such as those seen with Google's human sounding virtual assistant Duplex.

It is unclear what identity robots' voices should project to influence optimal liking and learning. Sometimes, a voice is used that is similar to the students', such as using a child's voice when teaching children $[31,32,61,111]$. Kose and Yorganci reported that this had a "positive effect" on children [61]. This could be attributable to the age of the voice, the naturalness of the voice (prerecorded), or a combination, leading to enhanced common ground between the robot and student. Alternatively, the platform default voice may be used. It seems appropriate that the voice should match the intended social role of the robot (as teacher, peer, etc.) if there is one, but voice selection is a matter that requires further exploration. Nonetheless, it is recommended that the voice be as natural as possible, mimicking the prosody, rhythm, stress, intonation, and accent of a native speaker of the target language [66, 74, 94].

Voice switching-switching from one voice to a distinctly different voice-might occur in a robot's storytelling mode, with robots that have both autonomous and telepresence capabilities, and with robots that can communicate in native and foreign languages. Park et al. handled this by having the robot say "Abracadabra" when changing its voice, so as not to confuse students [80]. Largely though, this is not addressed. How voice switching is viewed, including "perceptions of voice switching of multi-lingual robots[,] could be worth explicitly exploring in future work" [54].

Other factors influencing speech, such as volume and speaking rate, are sometimes adjustable $[20,117]$. Rate of speech should be modifiable in at least some situations to suit users' needs [23].

\subsection{Social Role}

Robots used in language learning can exhibit one of four social roles: (1) teacher, (2) teacher's assistant, (3) peer/tutor, or (4) learner. Alternatively, they may not be classified as a social other at all. When assigned the role of teacher, teacher's assistant, or peer, knowledge transfer may be unidirectional, from the robot to the student, or bidirectional. However, these roles vary in intended levels of authority and connectedness with the student, with the teacher role being particularly high in authority and the peer/tutor role being particularly high in connectedness. In the learner role, knowledge transfer is mostly unidirectional, from the student to the robot.

The role of teacher is used infrequently in RALL. In fact, educators have expressed discomfort with robots that are meant to be teachers, viewing them as intimidating [76] or competitors [80]. According to Osada et al., educators expressed that robots in the teacher role would face barriers to acceptance within the field [76]. Therefore, the teacher role is most commonly seen with telepresence robots, where a live teacher is present, as seen with References [63] and [119]. However, studies have also explored using two robots in conjunction to improve outcomes, with one robot meant to function as the teacher to another less advanced robot [46, 56]. After watching both robots interact, the robot in the teacher role would ask the human learner questions. This was meant to serve as a conversational model from which the human could draw. 
Autonomous robots acting as teacher's assistants does occur [42, 114]. For instance, Hong et al. gave Bioloid the role of teacher's assistant, having it give students commands and assign them tasks [42]. Likewise, the PET robot was used to teach students the alphabet and instruct them to repeat sentences after it [114]. The inclusion of robots as teaching assistants may have a positive impact on students' learning when used in addition to human instructors, as they can serve to lower the affective filter (see Section 5-Results on Affective Changes of Learners). As the robot is subordinate to the human instructor, this role is more likely to be accepted among educators compared with robots meant to be teachers. It is, in practice, the only choice when attempting to use autonomous robots in a teaching role in classroom settings, due to the technical limitations and malfunctions of such technology in an environment that demands flexibility, stability, and control.

The role of peer is seen more regularly (e.g., References [21, 57]). This can take the form of tutoring or co-learning. The tendency is for children to describe robots in this position as more of a friend than a teacher (e.g., References [87, 118]). Due to the use of higher degrees of connectedness between the student and robot, learners tend to find this role highly desirable [87, 118], which may speak to the popularity of using robots in this way. Peer/tutor robots are used in both group and one-on-one instruction.

Robots in the learner role take advantage of the care-receiving paradigm (e.g., References [32, 99, 117]). Prototypically, the robot is younger, smaller, and less knowledgeable than the student. There are a few reasons this role might be advantageous, such as when voice synthesis is not clear and students need to be comfortable expressing lack of understanding [31], when voice recognition is weak and it is desirable to increase students' tolerance of this issue [43], or to negate other mistakes without affecting the relationship [117]. In addition, this role has been utilized with the expectation that it will positively affect task motivation [47, 99].

Robots can also fail to invoke any social role. Broadly speaking, there are two reasons this might occur. First, this may be somewhat accidental, with students simply failing to classify it within the social hierarchy. For example, in Kose et al., children described NAO as a toy, while describing Robovie, a larger robot with the same role as NAO, as a peer [59]. This highlights that whether an agent is considered a social other may be independent from its actions. Further, it can be dependent on the group. In Chang, Lee, Wang et al. students seemed to treat the robot as a social other, while teachers failed to classify it as such, instead describing it as a tool [21]. To a lesser extent, this may also be dependent on the individual. In Wang, Young, and Jang, some students described Rocky as a peer or friend, while others labelled it a toy or doll [107].

Second, the lack of social role can be purposeful, as the robot is meant to function only as a tool (e.g., References [70, 81, 95]). According to Mubin et al., "the verbal articulations of the students had a direct influence on the Mindstorms robot, therefore we can hypothesize that the role of a tool for a robot might be better than the role of a peer, especially when it comes to language learning" [73:13]. This aligns with TPR theory (discussed in Section 6.4, Instructional Methods), which emphasizes a connection between learning and movement. Chang, Lee, Wang, and Chen also saw that children learned words used to control the robot better than words used within the learning task, though the task necessitated that they use these words at a much higher frequency [21]. There has been no research in RALL to indicate which social role is the best for language learning, or whether a social role should be utilized at all. It is conceivable that this would vary by type of language learning (comprehension vs expression), level (beginner vs intermediate vs advanced), and time (short vs long-term).

\subsection{Verbal and Non-verbal Immediacy}

Non-verbal immediacy is defined as creating a feeling of connectedness with others by smiling, gesturing, leaning in, engaging in eye contact, using a pleasant vocal tone, reducing physical 
distance, and the like. Verbal immediacy, however, is defined as using language in an attempt to create a feeling of closeness. One way to achieve this is by using students' names during the interaction $[50,66]$. Saerbeck et al. showed that a robot creating verbal immediacy, by using "we" instead of "you," using motivational phrases, and relating to students-along with presenting non-verbal immediacy behaviors-led to increased language learning and motivation among students [87]. However, it is difficult to conclude to which behaviors (verbal or non-verbal) this is attributable. In fact, when studied independently, verbal immediacy has been shown to have no effect on robot-assisted learning [54]. It should be noted that in this study the robot interacted with students one-on-one, and results of previous research show that verbal immediacy becomes more important with increasing class size [34]. Nonverbal immediacy, however, has previously been shown to increase learning [53]. As well, a meta-analysis on the effects of immediacy in human teaching found that non-verbal immediacy is more strongly associated with learning than verbal immediacy, which is very weakly positively correlated with learning, though both are meaningfully correlated with perceived learning and motivation [113]. Therefore, designing robots that display verbal immediacy, as well as non-verbal immediacy, is likely still important when considering long-term interaction.

\subsection{Non-verbal Cues}

Non-verbal cues used in RALL include head nods and happy faces [87] and smiling and thumbs up gesturing [114] corresponding to correct answers or success; head shakes and sad faces [87] and LED color changes $[3,61]$ corresponding to incorrect answers; eye gaze for attention guiding, turntaking, and emotional display [33, 80, 87, 117]; sound effects and music for emotional emphasis $[20,59,70,114,117]$ or to increase energy [81]; color and light changes to show emotion [59, 61, 87] or voice recognition [76]; and body movement and motion to show animation [70, 87, 114], express understanding [70], or emphasize spoken material [23, 114]. These cues may be executed in response to stimuli or used to create idling motions to make the robot seem more lifelike [81, 87].

Overall, there is a tendency to use facial expressions and body movements to convey action, intention, and emotion. This is because "human perception of a robot's emotional expressions plays a crucial role in human robot interaction" [66:40]. It can also affect students' emotions. When measured, Gordon et al. found that children's affective states change in response to nonverbal cues presented by a social robot [33]. Specifically, their emotion was positively affected after the robot performed such behaviors such as leaning in, nodding, and using positive utterances, and negatively affected after expressions of sadness [33]. Students' emotions, both pre-existing and created through interaction with the robot, can influence learning and the learning environment [106].

\subsection{Personalization}

Besides using an individual's name during the interaction, personalization can occur in three discrete areas. First is the customization of content to one's ability. Yorita, Botzheim, and Kubota used the concept of self-efficacy as one component in an algorithm designed to aid in learning [115]. That is, depending on how likely the robot was to get a response, the level of complexity of its speech would vary. The potential viability of this approach can be reflected in the results of Westlund \& Breazeal [109]. They found that "[c]hildren who played with a matched robot used more words, and more diverse words, in their stories than unmatched children" [109:65]. Though Schodde, Bergmann, and Kopp did not find a significant effect of difficulty level adaptation on learning [91], their study was likely too short to detect an effect (one short interaction vs eight interactions in the aforementioned study). In CALL, adapting content to the user's progress has been shown to aid learning [89]. This is consistent with the use of scaffolding and the belief that people learn in their zone of proximal development (ZPD)-while performing tasks that are at a 
challenging but achievable level of difficulty-concepts that were originated by Vygotsky and are often echoed in education today.

Additionally, feedback can be customized based on one's progress [27]. Instead of only considering responses to a given question, feedback can be adaptive to the overall trajectory of right or wrong answers.

Last, the robot's affect or engagement strategy may be modified based on its partner's emotional state, resulting in individualized verbal and non-verbal responses [33, 92]. It has yet to be determined whether these latter two adaptations correlate with enhanced outcomes in RALL, though they are strategies human instructors often employ.

\section{LANGUAGE LEARNING RESULTS}

According to Chen et al., language can be broken down into a four-level hierarchy, "from subword (e.g., phonemes, morphemes), word (e.g., semantics, morphology), clause (e.g., syntax/grammar), and up to discourse/text (e.g., conversation)" [23:547]. Robots have been used to influence learning at all levels. Results vary per area and are summarized below. As robot-assisted language learning is still a new field, more research is required in most areas before definitive conclusions can be drawn. Additionally, differences in form, voice, social role (Section 2), and instructional method (Section 5.4) may account for some of the variability in results. Previous work suggests there are no gender differences in how well males and females learn from robots [3, 4, 29, 61, 87, 101].

See Table 2 in the Appendix for a summary of results.

\subsection{Vocabulary}

The ability of robots to teach vocabulary is well documented in RALL (e.g., References [8, 31, 54]). For example, Movellan et al. showed a $27 \%$ improvement in vocabulary as compared to control words among toddlers [72]. Further, attesting to the usefulness of robots in learning, students working in child-robot pairs have been shown to stimulate more learning compared with childchild pairs [71].

That robots can improve students' vocabulary is perhaps unsurprising. A more interesting question is: How do robots compare with other technologies in their ability to do so? Studies suggest that, at least for simple vocabulary teaching, robots perform on par with iPads [110], and for that matter, human teachers $[110,112]$. All three served equally well for transferring knowledge of rudimentary vocabulary. However, children had a strong preference for learning with the robot over both the iPad and person [110], though this may be due to a novelty effect. Hyun, Kim, Jang, and Park also compared robots with computers and found they were both capable of increasing children's vocabulary, but there were no significant differences in their ability to do so [44]. Yet, the robot did significantly better than the computer at imparting other skills, such as reading, story comprehension, and general communicative ability. To belabor the point, the results of Chang, Lee, Wang, and Chen showed no difference in vocabulary learning when using a co-present robot versus a robot in virtual space; however, there were differences in reported motivation and engagement [21].

More nuanced results were obtained by Köse et al. when looking at sign recognition [60]. When signs were performed by a virtual or physical Robovie, there was no difference in recognition rates among adults with no previous sign experience and children with advanced knowledge of sign. Children with beginner's level knowledge, however, were better able to recognize signs when performed by the physical robot. They suggest that "prior knowledge... has an influence on the significance of physical presence" and conclude that young children in the beginning stages of language learning may benefit more from embodiment [60:545]. This idea that physical embodiment plays a more prominent role in learning for children and beginners is worth further exploration. 
These results reveal that, at least for most groups, the use of robots will not likely present an advantage in vocabulary learning over other technologies, at least in the short-term (as measured in days or weeks). The true benefit their use presents over 2D technologies may be in increasing the desire for continued training-by increasing motivation, interest, and engagement-and this may be important in long-term success. They may also contribute to content retention. In a fiveweek study by Alemi, Meghdari, and Ghazisaedy, students in the RALL condition were able to cover lesson material much faster than the non-RALL/teacher only group. They also exhibited greater retention of the material when tested two weeks later [8]. However, that the two groups covered material at different rates may suggest they were not equivalent. Further research should be undertaken to investigate the long-term effects of robots on vocabulary acquisition.

\subsection{Grammar}

The influence of robots on grammar is not well studied. In the one study to explicitly report these effects, robots significantly improved children's grammar ability as tested after eight weeks of study [66]. Both beginner and intermediate language learners saw improvements. However, how robots compare with other technology in their ability to expand knowledge in this area is untested.

\subsection{Pronunciation}

Few studies in RALL have directly measured pronunciation improvement. Over the course of an eight-week study conducted by Lee et al., children's pronunciation saw significant improvements [66]. This was true for both beginner and intermediate level students. Wang et al. also noted improvements in pronunciation, though interestingly, this was driven by students' desire to be understood by the voice recognition module [106].

\subsection{Speaking}

Improvements in speaking ability are consistently reported. Teachers have reported such improvements in their students [119], and improvements have also been recorded after experimental testing. In Lee et al., after using a robot for conversational practice, both beginner and intermediate students showed marked improvements in overall speaking ability, which was measured as a composite of pronunciation, grammar, vocabulary, and communicative ability [66].

In addition, robots were deemed as more effective than computers in advancing the speaking skills of four-year-olds [44]. Robots may also offer advantages to having students simply converse with each other [107]. In Wang's study, this was especially significant for learners in the bottom third of the class; it is possible that students in the top third of the class did not improve as the material taught was not difficult enough for them, but the reason is unclear. However, children of higher ability do improve more when taught by a robot that is matched to their skill level [109].

Additionally, the effect of using a robot to aid teachers has also been explored [42]. Though no differences were seen in speaking ability compared to a control classroom without a robot, significant differences were discovered in listening and reading skills.

\subsection{Oral Comprehension}

The effects of robots on oral comprehension are mixed. Neither Lee et al. [66] or Kanda et al. [50] saw any overall improvements in listening ability among beginning students. In Kanda et al. [50], however, those students who interacted with the robot more during the second (and last) week of the interaction showed significant improvement. It is important to note that in Kanda's study, interaction was voluntary at recess, so improvements might only be expected for children who interacted more with the robot. It could also represent a self-selection bias, where those students with better pre-existing English skills chose to interact more. In Lee's eight-week study, 
intermediate students actually had significantly worse listening scores at the conclusion of the study. "This finding can be explained by a number of factors such as the unsatisfactory quality of the text-to-speech component and the robots' various sound effects" [66:46].

By contrast, Hong et al. [42] noted improvement in the listening ability of students. This difference was significant even by comparison to a control group, a similar classroom environment, lacking only the presence of the robot. In another experiment, comprehension of four-year-old children using a robot improved over that of a control group who used computers [44]. Of note is that Hong et al. [42] and Kanda et al. [50] used pre-recorded voices, while Lee et al. [66] and Hyun et al. [44] used TTS. While use of TTS vs natural voice could potentially cause differences in understanding (as tested by human interlocutors with native accents), this suggests that other variables are also at play, only one of which may be the quality of TTS. Still, it is recommended that native speech be used in RALL, and if that is not a possibility, then the quality of TTS is high.

It is hard to completely reconcile the above findings. As well, how effects on oral comprehension when using robots compare to similar training when listening to audio from an app, computer, or virtual character is largely unstudied. It is important to assess if robots (due to their embodiment and sociality) offer unique advantages in this area. More research needs to be conducted into how using robots might (or might not) offer unique advantages in improving listening comprehension.

\subsection{Reading Comprehension}

Although it is likely that robots can help improve reading comprehension (as they do with other aspects of language), results comparing robot-assistance to other technology is lacking and inconsistent. Hong et al. measured changes in reading comprehension, comparing to computer and teacher-only (versus teacher+robot) conditions [42]. Compared to both controls, children made significantly more gains in the robot conditions. Hong et al. reported additional results for writing, but used the cloze test as their assessment metric, which is normally correlated with reading comprehension. Inconsistent with their findings from having students choose a picture corresponding to text they read, they found the RALL group did not improve significantly over their control.

\subsection{Writing}

With a series of three case studies, Jacq et al. examined how the NAO robot could be used as an accompaniment to a tablet to improve children's writing ability [47]. They employed the learningby-teaching paradigm, making the children responsible for teaching the robot. They also iteratively adapted their algorithm, having the robot learn letters at a certain rate, an intermediary between its starting state and the text the child wrote on the tablet. From observations and discussions with parents, they deemed the robot had caused rapid and evident changes in writing skills over the four sessions. They also noted that at least one child bonded to the robot, attempting to write it letters even several months after the study's conclusion.

\section{RESULTS ON AFFECTIVE CHANGES OF LEARNERS}

Though the results of how robot assistance in language learning compares with other technology is still an open question, the positive effect they produce on learners' affect is more consistent. Utilizing robots in this area has been shown to increase engagement during the task, interest in learning with technology, and motivation in learning the language. They also demonstrate effectiveness in this regard when used as an addition to human instruction, in addition to increasing confidence and decreasing anxiety when communicating. Some uncertainty does exist as to whether these effects will still prove prominent in comparison in the long-term.

See Table 3 in the Appendix for a summary of results. 


\subsection{Motivation}

Motivation is one of the most important and widely accepted factors in language learning success $[25,78]$. Adding robots into the learning environment has been shown to cause profound changes in students' motivation to learn the target language, even when tested after two months of use $[10,63,66]$. Lee et al. showed that this was even the case for learners already at an intermediate level, elementary school students with some proficiency with the language [66]. The positive effect of robots on motivation persists even in comparison to other technological systems [21] and with their addition to typical classroom settings [107, 114], though these studies have been much shorter. Over four sessions, Wu et al. tested the robot PET in the classroom, where it sang and danced, told stories, and helped children learn the alphabet and body-part names in English [114]. Both qualitative interviews and survey results supported the fact that adding the robot to the classroom led to a higher degree of motivation among students. It should be noted that robots that display higher non-verbal immediacy and that are more supportive will do better at increasing motivation than robots without these characteristics [87].

\subsection{Interest}

Related to motivation is the concept of interest. Interest, as defined here, is how much learners want to use the technology, as opposed to how much they want to learn the target language. Interest likely drives motivation in part. Many studies have demonstrated that learners are very interested in robotic tutors [27, 37, 63, 66, 114]. Even though this is probably true in comparison to other technologies [37], poor robotic design or implementation can negate any benefit [81]. As well, both You, Shen, Chang, Liu, and Chen and Kanda et al. found that interest in the robot fades over time, at around the two-week mark [50, 117]. This makes long-term studies of RALL particularly important. Strategies for prolonging interest should therefore be explored.

\subsection{Engagement}

Significant improvements in students' task engagement have been repeatedly reported in RALL. Students exhibit more concentration than when using computers, audio, books, or virtual agents $[21,37,96,100,108]$. Using a disembodied voice and a virtual robot as controls, Wedenborn found that adult learners reported significantly more engagement when learning with the physical robot [108]. It has also been reported that young children voluntarily spend more time learning with robots compared to other technology [44]. Increased engagement even seems to occur when the students are the ones operating the robot. Tanaka et al. observed that students using a telepresence robot during a language lesson responded to the teacher more than when they used Skype [100].

\subsection{Confidence}

Four studies have reported that students' confidence and willingness to communicate have been strengthened as a result of RALL $[42,63,66,107]$. This is likely due to a sense of achievement and the relaxed atmosphere that the robot creates [66], which might be especially beneficial to learners who are more anxious to speak [20]. While no studies have compared using robots with other technology, two have found positive effects on confidence when using a robot in conjunction with a human teacher. In Hong et al., the teacher performed the same lessons in both classrooms, but utilized the robot as an aid in some tasks, such as storytelling and read-aloud activities [42]. This led to significantly more confidence, as measured by questionnaire.

\subsection{Anxiety}

Anxiety reduction is often cited as a primary reason to use robots in language learning, since learning anxiety is very common [70]. Alemi et al. (2015) and Alemi et al. (2017) confirm anxiety 
reduction due to RALL implementation while learning, even over 10 sessions of use [5,10]. In Alemi et al. (2017) the robot was programmed to make mistakes, so children would learn that it was okay for them to make them [10]. Future consideration should be given to whether this reduced anxious state will transfer when students need to communicate with real people [65, 70]. Though Wang et al. found that learners reported being anxious to use their acquired skills with others at the same levels, the robot plus teacher group reported being more willing to do so, compared to the teacher-only group [107].

\section{FRAMING THE RESEARCH}

\subsection{Ages}

For the most part, children between the ages of 3 and 14 years have been studied. There has been only one study with children under 2 [72] and few studies with adult participants [39, 46, 56, 59, 60, $62,69,81,108]$. There are probably several reasons for this, including the fact that children learn language easier than adults $[16,48]$, that infants and toddlers can be challenging to handle during the course of an experiment and often require special methodological approaches to testing (e.g., preferential looking tests for pre-verbal infants), and that many countries require foreign language class enrollment for children during elementary school. Worth noting is that age may influence how learners perceive technology and the appropriateness of a given intervention. Though not many studies have looked at this, one study did find that younger students (first-graders) were more interested and interacted longer with the robot than older students (sixth-graders) during the first week of the study [50].

\subsection{Skill Level}

Beginners have primarily been the target in RALL. There are few recorded studies that examine how robots might benefit those with previous language experience [46, 56, 66, 69, 85, 95, 118]. Likely, this is because technology in its current state makes interventions more feasible for beginning language learners.

\subsection{Languages}

Predominantly, RALL has targeted teaching a foreign language-and this language is typically English. However, languages run the gamut, including artificial languages such as Toki Pona and ROILA and non-verbal languages such as sign languages. Only four studies have focused on native language development $[47,61,72,112]$. Differences exist between possible strategies to teach foreign and native languages. For word learning, native language learning requires the mapping of a name to an image of the target, while foreign language learning may only employ mapping a new name to an existing name space. As well, in native language learning conversational ability arises naturally after prolonged language input-grammar rules and colloquialisms are not explicitly taught, with children receiving additional input and implicit and explicit feedback to improve. While foreign language learning can be taught like this, it is often accompanied by explicit grammar rules and translations.

\subsection{Instructional Methods}

There are too many language learning methods to recount, but several popular strategies have been employed in the aforementioned studies. One popular approach in RALL is to use total physical response (TPR) (e.g., References [6, 42]). TPR was created by James Asher in the 1960s and requires movement in response to language. Students learn by physically manifesting commands from the instructor, or sometimes from observing the instructor's response to commands given. 
The direct method (a.k.a. natural method) focuses on the development of conversational ability [19]. Similar to how we learn our natural language, this method can be employed in foreign or second language learning. Only the target language is heard-there are no translations from or to one's native language and no explicit grammar rules are taught.

Communicative language teaching (CLT) also focuses on conversational ability-social interaction is both the goal and the means by which the goal is achieved [90]. Task-based language teaching (TBLT) is based on CLT, but concentrates on having learners complete explicit tasks [28]. Both CLT and TBLT are quite popular in RALL, especially in research coming from Asia (e.g., References $[22,66,114])$. They were established in response to an older technique, which is still used, called the audiolingual method (ALM). ALM aims to foster communicative ability through repetition and memorization, focusing on drills that convey correct grammar [84].

All these methods are quite different than the grammar-translation method, where the emphasis is on learning grammatical rules and memorizing vocabulary, and speaking is deemphasized completely. As well-although not language teaching methods per se-storytelling and game play are commonly employed in RALL (e.g., References $[8,13,57,58])$. There is good reason for this. Storytelling, especially collaborative storytelling, is a particularly good interaction scenario as it serves as comprehensible input and promotes comprehensible output [40]. It is one of the first ways children engage fully with language, coming before they learn to read or write, and can benefit language learners of any age or skill level $[79,86]$. Additionally, gamification has been used in many fields including education and has been shown to increase motivation and engagement [35]. As previously mentioned, these affective factors are important in language learning, as they have an influence on ultimate success. Both storytelling and gamified learning are likely more engaging than some other methods that might be used (e.g., use of reading comprehension sets) that are not seen much in RALL. They also take particular advantage of the robot's embodiment and sociality.

The point here is not to make suggestions about what method should be used, and in reality, multiple methods are often used at once (principle eclecticism). The point is to draw attention to the fact that in RALL, researchers make choices about how to use robots, albeit not always intentionally, and these choices will have differing impacts on learning outcomes.

\subsection{Location}

Though RALL research has taken place all over the world, research from Asia (South Korea, Taiwan, and Japan) make up about $40 \%$ of the literature surveyed. While there is likely no reason to believe that results of people's ability to learn with robots vary by country, it is conceivable that due to cultural norms and differing depictions of robots in the media, factors such as optimal non-verbal cues and desired form may vary. Table 1 illustrates that many robots, with the exception of NAO, are often country-specific. As well, study implementation also may vary by location. For instance, CLT and TBLT methods are used often in Asia, but less so elsewhere. These factors may account for some of the differences in study results.

\subsection{Setting}

Nearly all studies have taken place in a classroom or on a school's premises. Some studies have engaged children when they are in groups, while other studies examine the effects robots have on individuals when they are interacting individually with the robot. There is definitely a balance to be had. While learners might find it more fun and comfortable to interact in a group [107], those who receive one-on-one tutoring usually score much better than those who receive classroom education [17]. In the educational HRI literature, this one-on-one interaction with robots has led to learning gains one standard deviation above the mean [67]. It is advantageous, therefore, to develop robots for these dual contexts, or to develop robots both specifically to interact with individuals and those 
meant to interact with groups. As well, research outside the school (i.e., in the home) should be conducted to determine how individuals might interact and learn from robots in less structured environments, especially since free time that might be devoted to learning is more abundant in the home.

\subsection{Length}

Study length tends to be short, with about half of all studies taking place in one session. Even longer studies (e.g., 1-2 months), tend to be composed of a limited number of visits (e.g., 4-8 sessions). A notable exception is Lee et al., which was 16 sessions [66]. Long-term studies are critical as a novelty effect has been found in human-robot interaction. Individuals are originally excited about the introduction of robots, which in turn affects their behavior (often increasing interaction time and, conceivably, reported desirability and likeability), but this novelty effect begins to wear off after more constant exposure. Though there is not an exact time where this novelty effect begins to fade, it has previously occurred during the second week of daily exposure [50]. As very few studies have been conducted for longer than 4 sessions, it is hard to say whether learning effects might be amplified over the long-term, motivation effects may be muted, or the reverse. If the hope is to start using this technology more consistently in real-world settings in the near future, as it should be, then more long-term, numerous sessions studies need to be conducted.

\subsection{Power}

Many studies on language learning outcomes (Appendix, Table 2) have small sample sizes. Therefore, they may lack sufficient power to detect an effect. Most studies comparing the effect robots have on vocabulary learning to other technology are between-subjects experiments comparing post test scores of both groups, with total training time for subjects lasting under 30 minutes. Even if we were to assume that the effect robots have on vocabulary learning is moderate (Cohen's kappa $=0.5$ as consistent with conventions in social science research), which is likely on the high end of what might be reasonably expected, then a sample size of 128 would be needed to detect an existing effect $80 \%$ of the time. As can be seen in Table 2 in the Appendix, no studies broach this number. In fact, most studies are better equipped to detect an effect that is at least one standard deviation above the mean of the control.

Part of the reason an effect may be found more readily in speaking, is that effect sizes are probably much larger (as robots likely are particularly beneficial in this role), many studies are withinsubjects experiments (which requires significantly less participants to detect an effect), studies tend to be longer (increasing the effect of the intervention on each group), and often pre-tests are conducted (with measures of improvement pre-test to post-test as well as between the post-test scores of experiment and control groups). For instance, Wang 2013 did not find an effect when performing an independent t-test but found an effect when using a paired t-test. As it is often difficult or too expensive to include a lot of subjects in HRI experiments, within-subjects designs with counterbalancing present distinct benefits over between-subjects designs, though of course, they are not appropriate in every situation.

Studies should therefore be interpreted with attention paid to how big an effect they can detect. As many studies are underpowered to detect small and moderate effects, much (but not all) of the research in Table 2 in the Appendix is only capable of detecting large differences between groups. It is possible that this is desirable. As robots are expensive relative to other technology (e.g., computers, iPads), it may only be of practical importance to know if using robots will improve outcomes substantially. 


\section{DISCUSSION}

\subsection{Challenges}

Compared to other types of robot-assisted learning, robots' speech recognition presents special challenges in language acquisition. Speech recognition can be faulty under "perfect" conditionsspeech produced by native speakers in quiet environments-due to differences in speakers, environmental noise, microphone quality, and language ambiguity (such as the presence of homophones or issues in detecting word boundaries in continuous speech) [82]. Speaker differences that may result in variability in automatic speech recognition (ASR) include the age, gender, speech rate, and regional dialects of speakers [82]. Research is underway to ameliorate these issues, but they are far from solved.

Since participants in RALL studies are often children, it is of particular relevance to address the shortcomings of ASR in respect to this population. When attempting to detect the speech of children using ASR systems trained using adult speech, accuracy is reduced significantly, with word error rates 2-5 times greater than those for adults [83]. There are publicly available child-specific corpora that can be used to train ASR engines to improve recognition rates [30]. However, a paucity of relevant corpora for children still exists. Even with the use of corpora trained with children's speech, recognition rates are still not as high as they are for adults. Children exhibit greater developmental changes and variability in speech patterns [98], yet they are treated as a homogeneous group. Collecting data specific to the target population's age and other demographics can improve error rate, but this method relies on intensive data collection that may not be practical for ASR systems meant for more general use [30]. Therefore, attempting to adapt adult-trained ASR systems to children's speech is also common [30].

Human understanding of speech is distinctly multimodal, with non-verbal cues serving to clarify or bolster meaning. Using such cues to improve the accuracy of such systems has been proposed [82]. Additionally, constraining user output to limit possible replies has been suggested and applied with success [24]. Kennedy et al. (2017) evaluated automatic recognition of naturalistic child speech within HRI. Their work supports using multiple cues in addition to speech, such as a touchscreen, creating interaction scenarios to constrain learners' responses, and constraining what the ASR system can recognize. The authors additionally conclude that, for optimal speech recognition, the microphone is best placed within the robot, instead of within the environment, that the robot be able to track sound and orient itself toward it, and that the child be located in the best possible position in front of the robot [55].

It is important to realize that these issues with ASR are present for fluent language speakers. Language learners produce varied and unique errors that those who have fully acquired the language do not, and this amplifies speech recognition issues. These errors may be syntactic, semantic, or morphological. There may also be phonetic (pronunciation and accent) and pragmatic (contextual and real-world usage) differences that arise. There is still quite a ways to go to make ASR robust for use by language learners in naturalistic contexts, but this step is needed if robots are most useful in the conversational aspects of language learning. This makes the adaptive strategies mentioned earlier even more critical, as well as the employment of other strategies, whether they be based on technology or human intervention. Teaching methods, population-specific educational goals, and current technical means should inform when, if, and how to deal with such occurrences.

When learning a language, it is also critical that the robot's speech be clear and correct. While this is favorable in any robot application, if learning occurs in a language where fluency has already been reached, reasonable interpretations can be made to the intent of the speech. This is more difficult when hearing a language in which one is a beginner and where the speech output serves as a model to mimic. 
Of course, there are several other challenges, such as designing for long-term interactions, reducing cost to make robots more commercially available, and getting teachers and users who may not have a technical background competent and comfortable in their operation. However, these are issues that are present in other robot-assisted learning areas, and indeed, in social robotics and HRI more generally.

\subsection{Language Learning Theories}

Using robots in language learning aligns with practical guidance on employing a number of theories of language learning. Three prominent theories of language learning-innatist (a.k.a. nativist), behavioral, and interactionist-hold different implications for teaching; however, these strategies are best combined in practical language instruction [75]. Per Nor and Rashid (2018) behavioral theory suggests that positive and negative reinforcement are needed for language learning, along with corrective feedback. Innatist theory suggests the need for comprehensible input and an environment that reduces anxiety as much as possible. Interactionist theory suggests that language is best learned when interacting with social others and with the goal of social interaction, and that teaching should be within one's zone of proximal development (ZPD), what one can achieve with guidance [75]. The addition of robots is most obviously connected to this last theory. By using an embodied agent that is more readily interpreted as a social other that can be communicated with, robots should be better than other technology for supporting language learning. Strategies for further supporting learning using robots align with practical implications from both innatist and behavioral theory; that is, the importance of feedback and personalization, the benefits of which are also supported by RALL specific research highlighted previously.

As evidenced by research thus far, the clearest benefit of using robots over other technology and in addition to human instruction is that they lower the affective filter. Based on Krashen's affective filter hypothesis and literature validating the role of affect in language learning [68, 93], it is probable that robots' ability to lower the affective filter (if more than a novelty effect) will also allow for the processing of more comprehensible input and thus promote learning gains.

\subsection{Practical Research Recommendations}

It seems that certain robot characteristics likely result in the most preferable outcomes. Therefore, recommendations can be made for researchers studying the effects of robots on learning or affect. First, the robot should be anthropomorphic or cartoon-like, though cartoon-like robots may be especially desirable for elementary-school-aged and younger children. The voice of the robot should be as natural as possible, preferably a pre-recorded voice exhibiting natural prosodic cues. If practical constraints limit this ability, then the TTS system used must be as natural as possible, showing clarity and prosody. If using a pre-recorded voice would present a confound when comparing the use of robots with that of other technology, TTS on par with the comparison technology may be preferred. Since all social roles the robot can exhibit seem to positively impact learners' affect, the peer/tutor role, where the robot is higher in connectedness and lower in authority, should be used. This is due to its high desirability among students and its higher acceptance among educators than the teacher role. A robot in the peer/tutor role also can serve as a guide so students are challenged to stay within their ZPD, which robots in the learner role do not do. The robot should exhibit multiple ways to establish non-verbal immediacy (for example, eye gaze, gesturing, smiling). Ideally, the difficulty of the task should also be personalized and evolve with the student's ability. If the technology used prevents such personalization, at minimum, when conducting between subject studies, children should be tested beforehand and pseudo-randomized into groups based on pre-test scores. These rules, of course, can and should be bent for researchers studying optimal robot design, thereby providing more evidence for the characteristics robots should have 
to impact higher degrees of liking and learning. However, when comparing two different robots in the lab or "in the wild" it would be advisable to hold most of these variables constant between the two implementations. In sum, these guidelines, if followed, will facilitate better comparisons between studies. They also serve as design advice for robots meant for language learning, given what we know today.

Regarding the study itself, one-session studies have not gotten us closer to assessing how well robots work for improving language learning or long-term effects on the affective filter. Therefore, it is highly recommended that future studies meant to study the effects of robots in one of these two areas be at least eight sessions long. For quantitative studies with a between-subjects design, a minimum of 34 participants (representing the sample size needed to detect a "large" effect size) is also strongly recommended.

\subsection{Gaps in Knowledge}

In many ways, this review serves to raise more questions than it answers. RALL is a nascent but blossoming field, with much research still needing to be conducted. Some of the questions that were raised in this review, which may serve to guide such future research, are as follows:

- Are robots best employed in a particular area(s) of language learning, and if so, where are they best suited?

- How should robots used for language learning purposes look?

- Does more learning occur with agents when people prefer the form of the robot?

- What age, gender, and cultural effects should be considered when designing robots' form?

- Is exact robot form more important when there is physical presence compared with video presentation, as far as learning gains are concerned?

- Is physical presence more important in learning for children and/or beginners?

- What identity should robots' voice project?

- Should they employ voice switching (for instance, to expose learners to multiple accents or to handle native and foreign languages) and if so, how should they handle this?

- What social roles should robots exhibit or are they best used as tools in language learning?

- Should the robots' affect and engagement strategy be personalized to the user for greater effectiveness?

An additional, previously unraised question is, are robots' use of non-verbal cues for sociality enough for an edge over learning with other technology, or must these cues serve to bolster meaning (pointing to or directing eye gaze to an object when speaking about it, representing it with gestures, or reinforcing meaning with other non-verbal cues, such as lights or sounds)? Largely, these questions relate to the robot's embodiment or the interaction of the robot's form with other factors. Different conclusions may arise when studying various attributes together, compared with studying them divorced from one another (for instance, the ideal voice for a robot may be different than that of a disembodied voice, as people may expect voice and body to seem consistent).

\subsection{Agenda Setting}

In setting an agenda going forward, a few things seem apparent. First is that most of the work done in this area has focused on vocabulary learning, and it does not seem that learning gains are significant in this area over the short-term. Researchers need to transition to studying how robots can be used to improve language production, comprehension, and accent. As well, studies need to examine long-term effects of using robots on motivation. If robots do not present statistically better outcomes for language learners over identical learning time periods, but they do spur students to study longer and in a more fully engaged fashion, then this alone may justify the use of robots. If 
learners are more prone to voluntarily continue pursuing their language learning goals when they otherwise would not, then this equates with better outcomes overall. Furthermore, if robots cause reduced anxiety compared to other technology, or when used in addition to human instruction while using newfound language skills with human speakers, then this alone may also make the technology valuable to language learners. Furthermore, more work should be conducted on how robots should be designed (role, voice, form, non-verbal behaviors, etc.) to improve educational goals.

\section{CONCLUSION}

This survey aims to present an exhaustive overview of previous studies in RALL, from 2004 (its inception) to 2017. It distills many of the common themes and important findings into four main sections: (1) characteristics of robots used and how they do or may affect language learners, (2) results of how robots have influenced language learners' success in each area of language, (3) results of how robots alter learners' affect during the teaching process, and (4) study information and critique that allows more interpretability of the previously discussed findings.

There is also much ambiguity around the ideal design(s) of robots for use in language acquisition (best form, social role, non-verbal cues, etc.), though a few things can be stated. The first is that the voice of the robot should be as naturalistic as possible, having prosody cues and an accent similar to that of a speaker of the target language. This is a recommendation that may differ from one made in any other area of human-robot interaction and social robotics. Second, robots should display verbal and non-verbal immediacy, though non-verbal immediacy is of particular importance. Finally, robots should exhibit personalization to the user, at least in individualizing the level of difficulty to the learner, but likely in other areas as well.

The main findings as they relate to learning are: (1) robots are able to help individuals of all ages learn language; (2) robots do not seem to be able to teach vocabulary more effectively than other technology, though preliminary research might suggest that all technology is also on par with human instruction, at least in the short term; (3) whether robots are superior to other technology in teaching other aspects of language (listening comprehension, reading comprehension, speaking, etc.) is still largely an open question, though current research suggests that they may offer advantages when used to foster speaking ability; (4) robots seem to aid learning when used as an accompaniment to human instruction; (5) evidence is strongest that robots have a positive effect on language learners' affective states (e.g., motivation to learn, anxiety when using the language, engagement in the task, and confidence when speaking), both when compared to other technology and when used in tandem with human instruction.

It should be noted that, unsurprisingly, robots are not yet suited to fully replace language learning with humans. In comparing people's perceptions of conversing with a robot versus a human in a language café, people ranked their conversations with people as superior in nearly every regard [69]. This had a lot to do with the human's capability to give appropriate feedback and guidance. The one exception was the evaluation of listening comprehension, where, especially beginners, felt the robot was easier to understand.

However, the goal is typically not to replace human teachers, only to supplement their instruction. It is possible that robots may supplant other technologies, but it is still open to debate whether the pros and cons of such replacement balance out in favor of robots. Much work still needs to be done to find out how to best use and design robots in RALL.

\section{A APPENDIX}




\begin{tabular}{|c|c|c|c|c|c|c|c|c|c|c|}
\hline 总 & 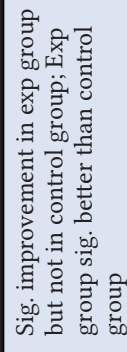 & 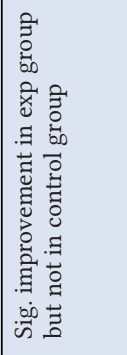 & 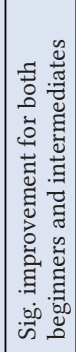 & 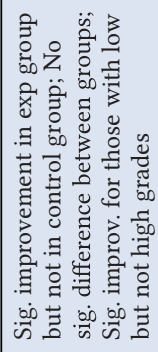 & 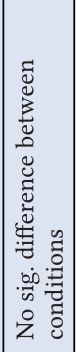 & 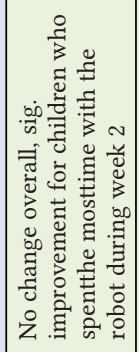 & 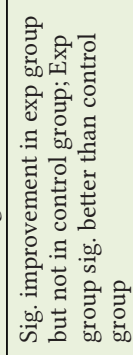 & 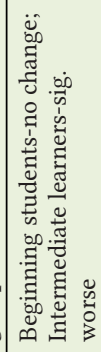 & 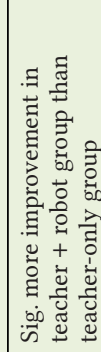 & 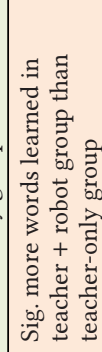 \\
\hline 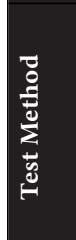 & 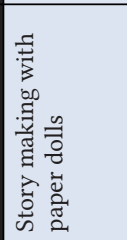 & 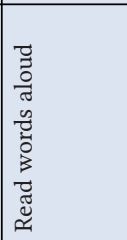 & 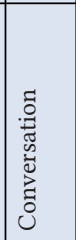 & 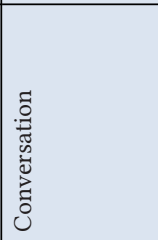 & 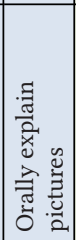 & 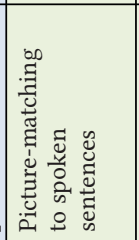 & 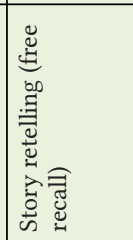 & 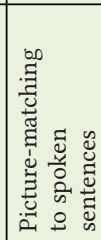 & 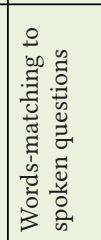 & 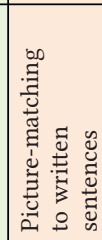 \\
\hline के & 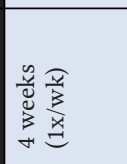 & 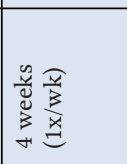 & 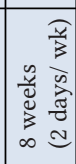 & \begin{tabular}{|l}
0 \\
$\vdots$ \\
0 \\
$\vdots$ \\
$\vdots$ \\
$\vdots$ \\
$z$ \\
$z$
\end{tabular} & 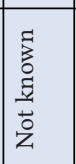 & 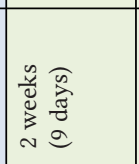 & 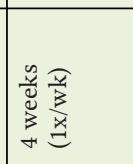 & 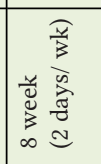 & 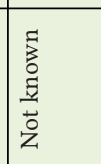 & 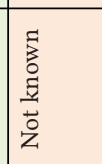 \\
\hline $\begin{array}{l}\overrightarrow{5} \\
\frac{3}{3} \\
\vdots \\
0\end{array}$ & $\cong$ & 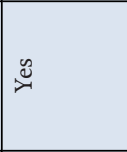 & $\stackrel{\circlearrowright}{\ddots}$ & 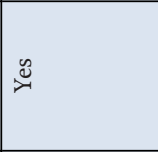 & $\underset{\nu}{\circlearrowright}$ & 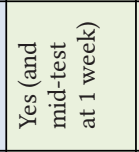 & $\cong$ & $\cong$ & $\cong$ & 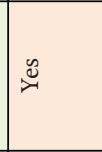 \\
\hline 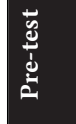 & 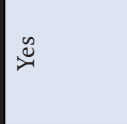 & $\underset{\nearrow}{\circlearrowright}$ & $\stackrel{\circlearrowright}{~}$ & 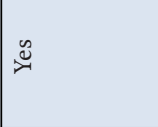 & ż & 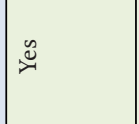 & $\stackrel{\circlearrowright}{~}$ & $\stackrel{\circlearrowright}{~}$ & ż & ż \\
\hline 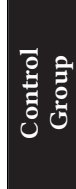 & 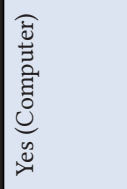 & 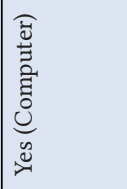 & ż & 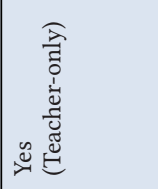 & 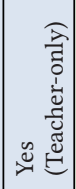 & z & 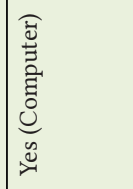 & $\ddot{z}$ & 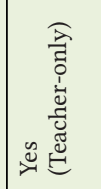 & 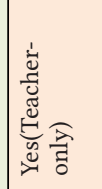 \\
\hline 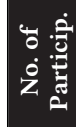 & m. & $\ddot{m}$ & $\vec{\sim}$ & $\tilde{6}$ & in & 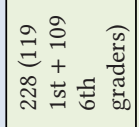 & mे & $\vec{\sim}$ & in & in \\
\hline 兑 & 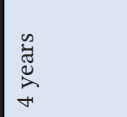 & 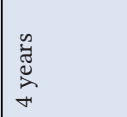 & 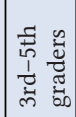 & 焉 & 至 & 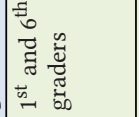 & 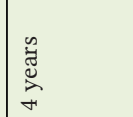 & 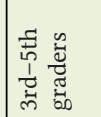 & 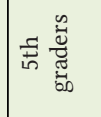 & 㱐 \\
\hline 死 & 蛋 & 蛋 & 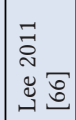 & 吕 & 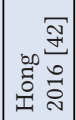 & 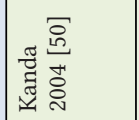 & 离离 & 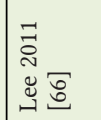 & 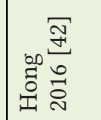 & 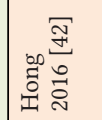 \\
\hline 言 & 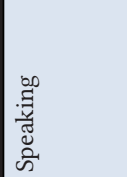 & 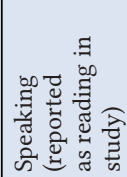 & 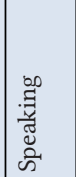 & 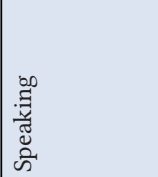 & 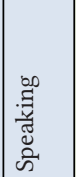 & 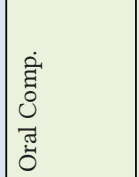 & 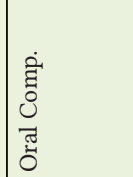 & 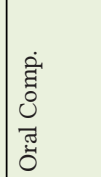 & 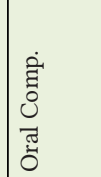 & 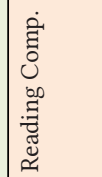 \\
\hline
\end{tabular}




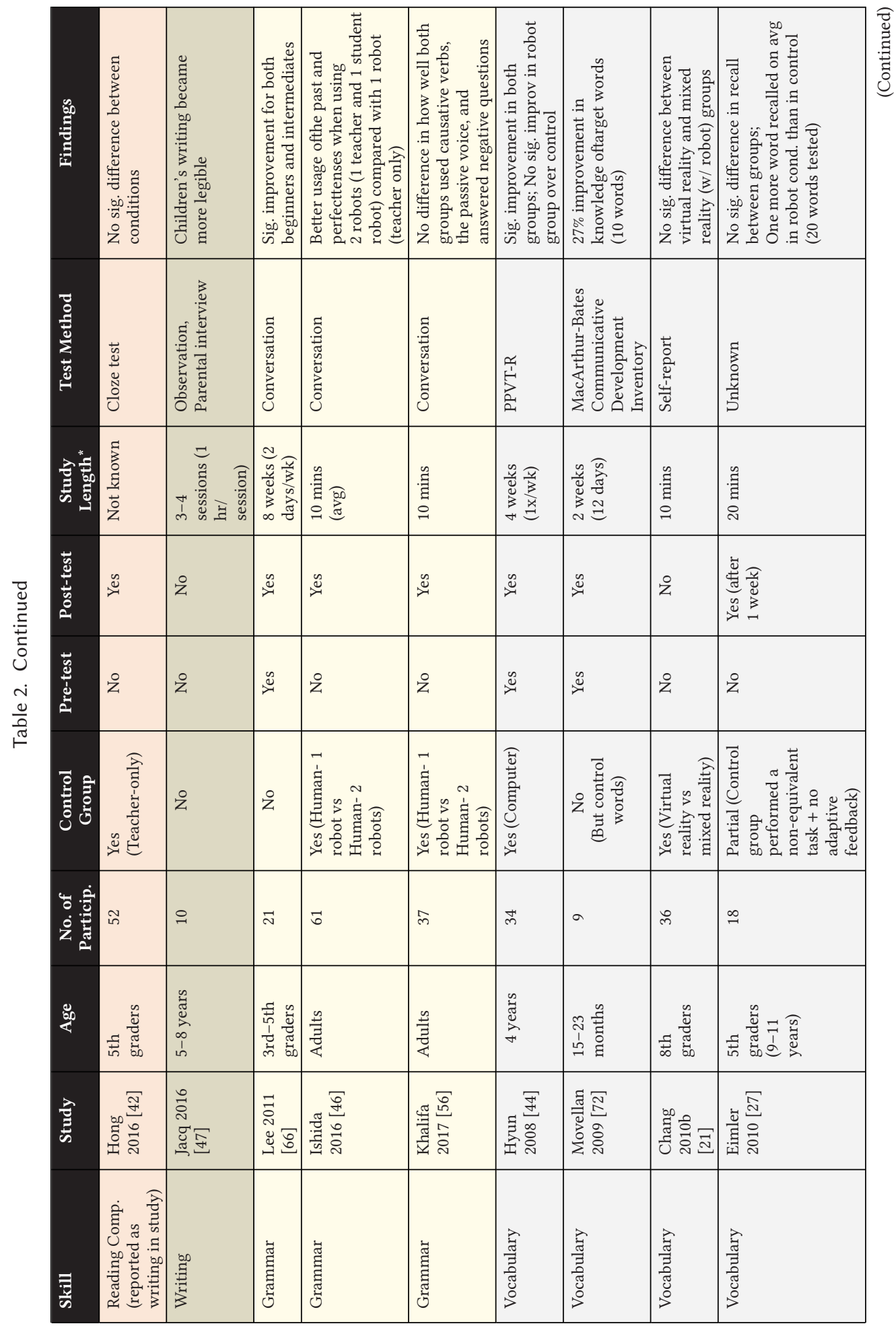




\begin{tabular}{|c|c|c|c|c|c|c|}
\hline 总 & 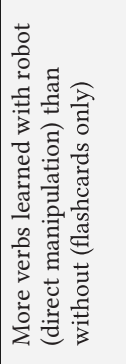 & 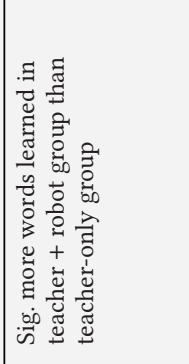 & 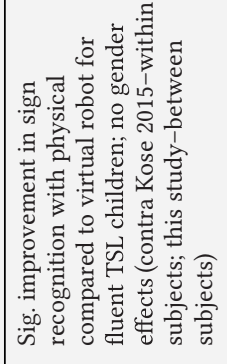 & 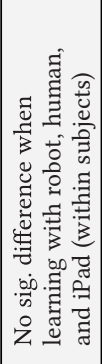 & 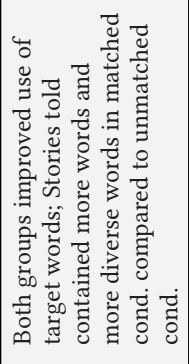 & 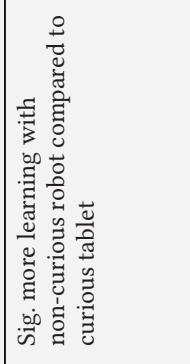 \\
\hline 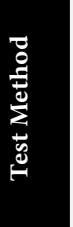 & 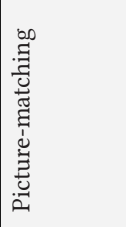 & $\begin{array}{l}5 \\
5 \\
0 \\
5 \\
5 \\
5\end{array}$ & 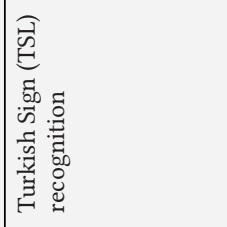 & 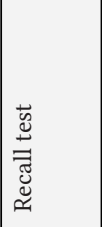 & 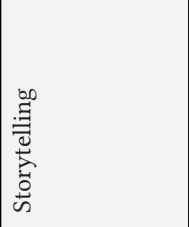 & 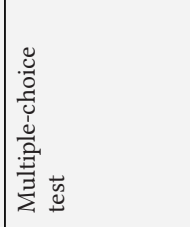 \\
\hline 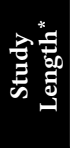 & 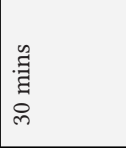 & 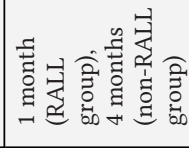 & 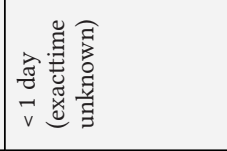 & 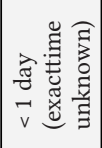 & 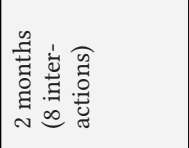 & $\begin{array}{l}\text { 青 } \\
\text { 总 }\end{array}$ \\
\hline $\begin{array}{l}\overrightarrow{0} \\
\frac{0}{0} \\
\frac{1}{0} \\
0\end{array}$ & 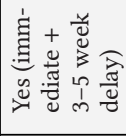 & 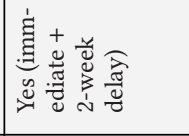 & $\cong$ & $\cong$ & $\cong$ & $\cong$ \\
\hline 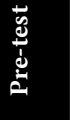 & 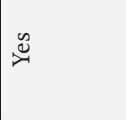 & 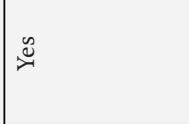 & そ & 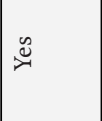 & 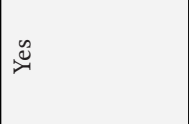 & 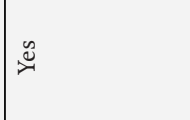 \\
\hline 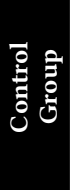 & 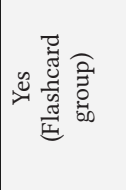 & 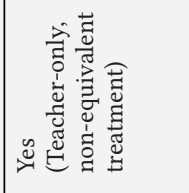 & 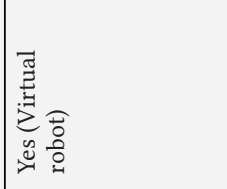 & 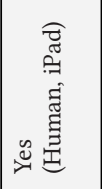 & 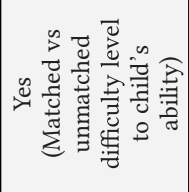 & 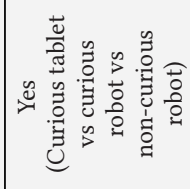 \\
\hline 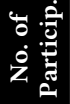 & $\approx$ & fi & $\stackrel{\infty}{\sim}$ & $\Rightarrow$ & $\infty$ & $\stackrel{\infty}{+}$ \\
\hline 总 & 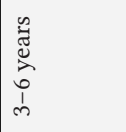 & 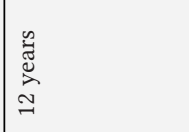 & $\mid \begin{array}{l}0 \\
\vdots \\
5 \\
2 \\
0 \\
1 \\
\alpha\end{array}$ & 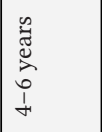 & 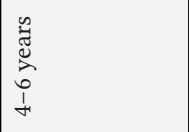 & 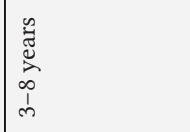 \\
\hline 死 & 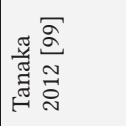 & 离 $\frac{\infty}{\stackrel{\infty}{*}}$ & 意 & 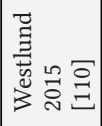 & 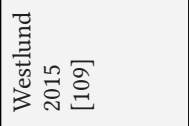 & 竞 \\
\hline 豆 & 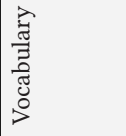 & 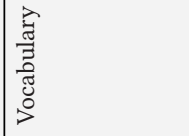 & 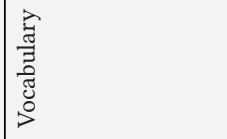 & 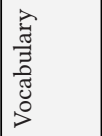 & 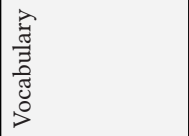 & 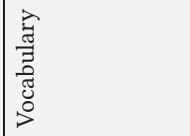 \\
\hline
\end{tabular}




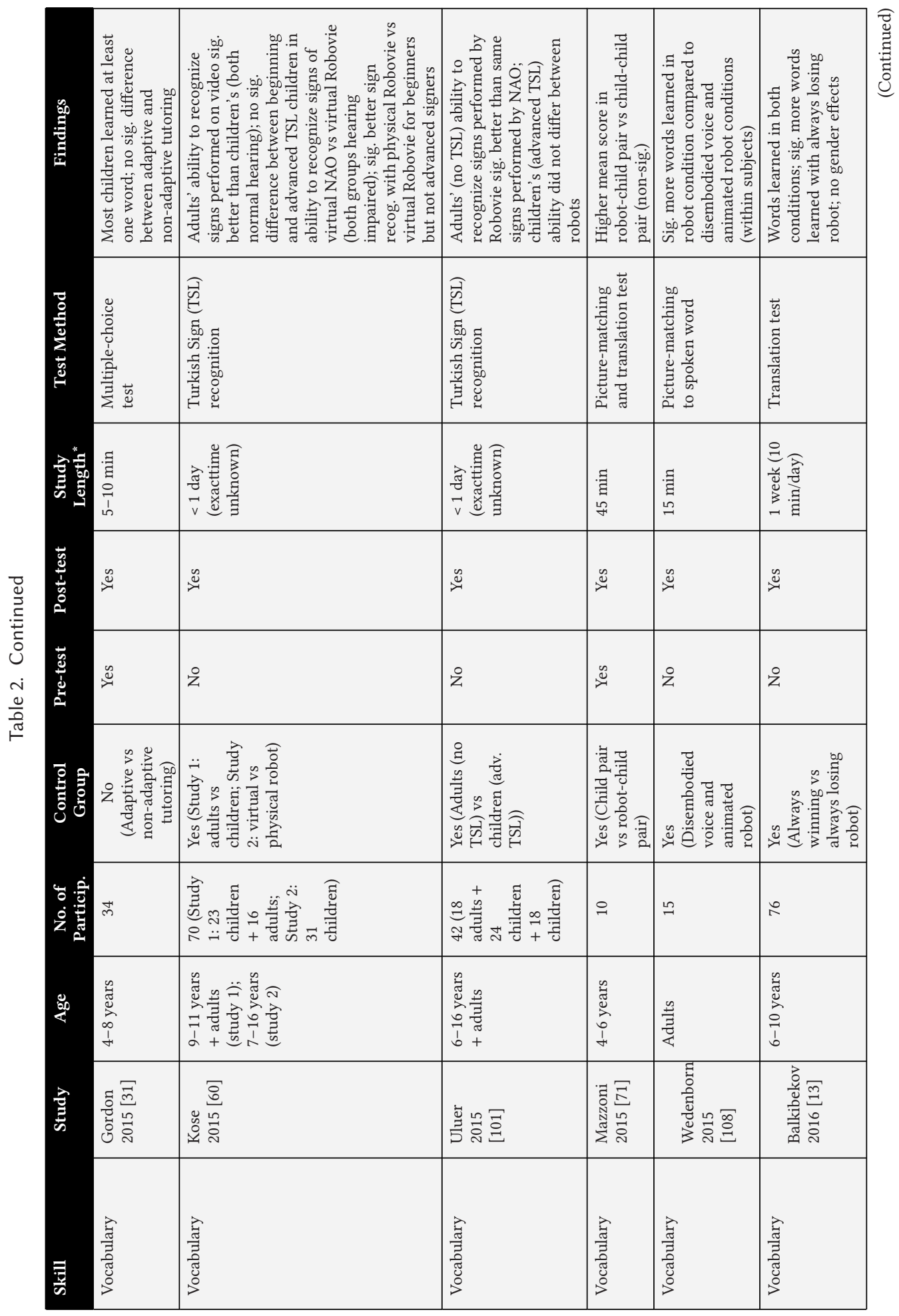




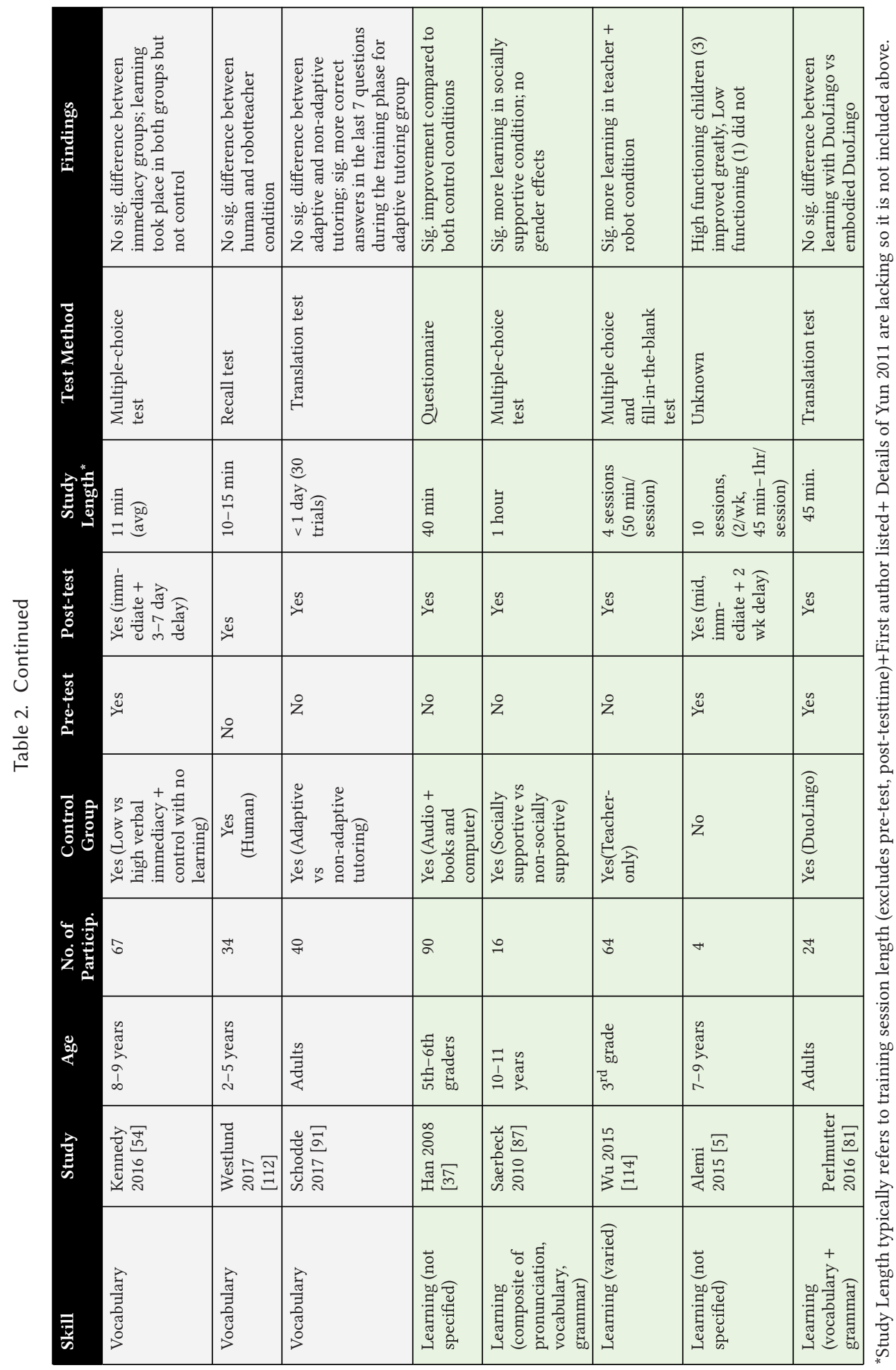




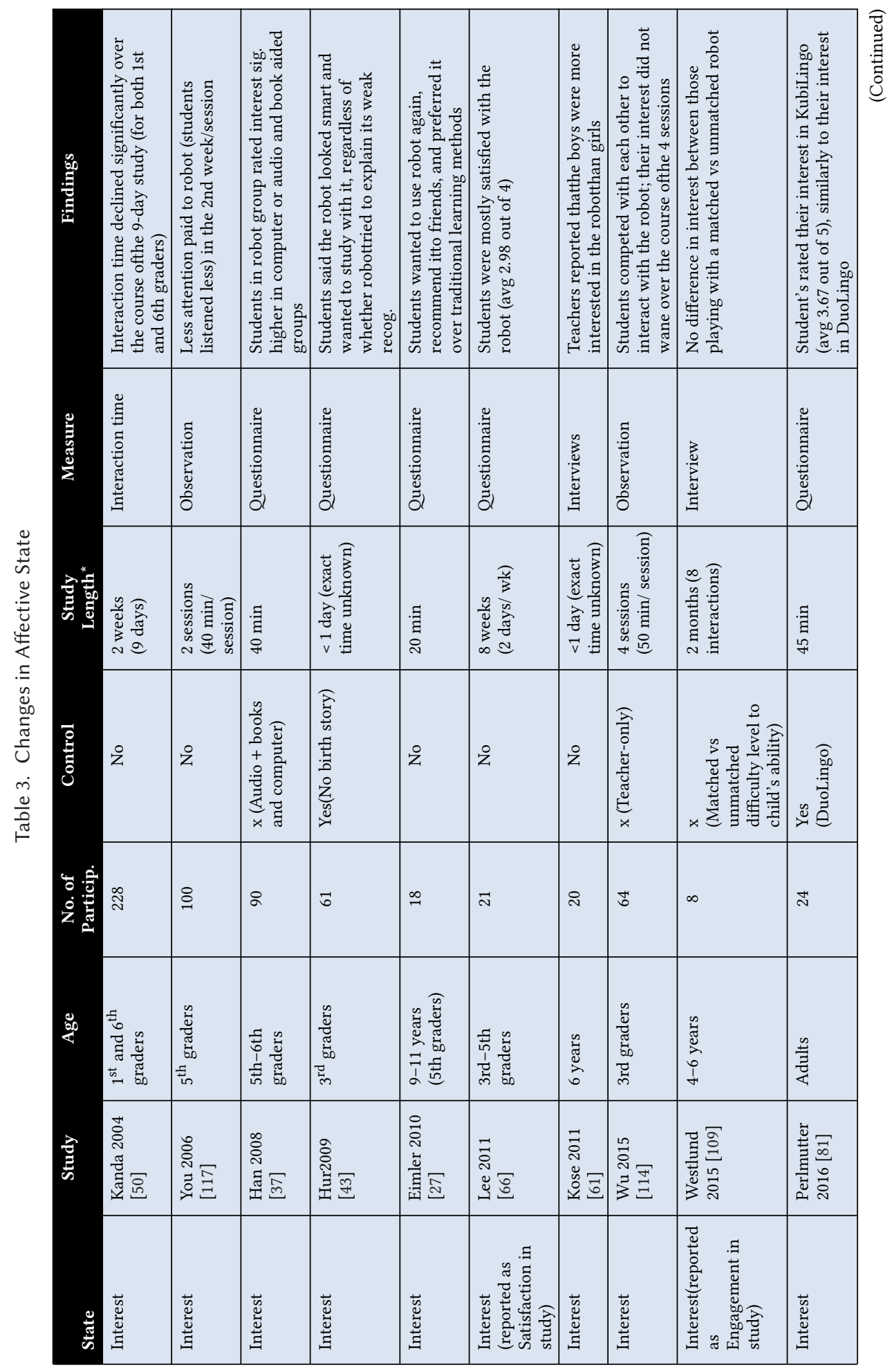




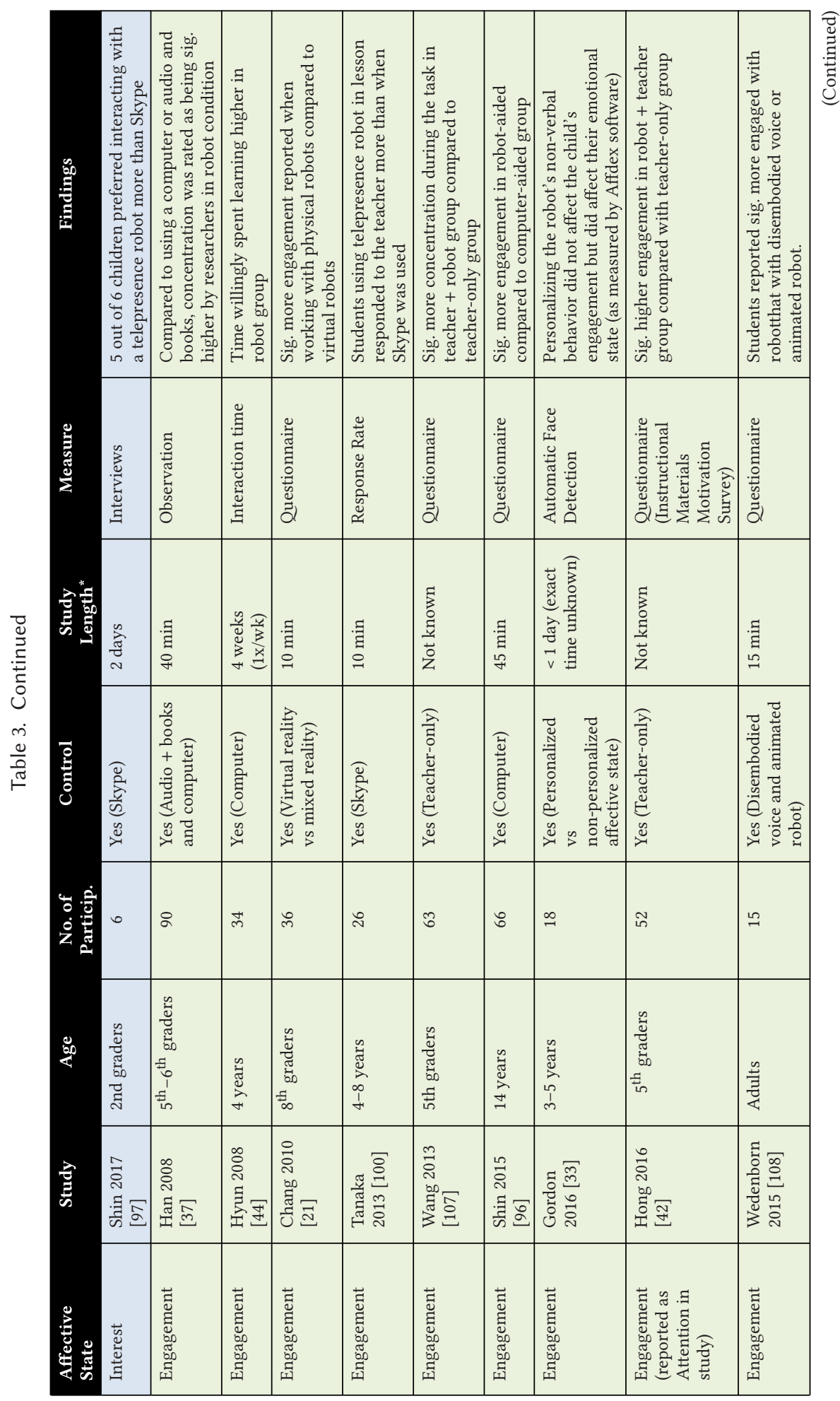




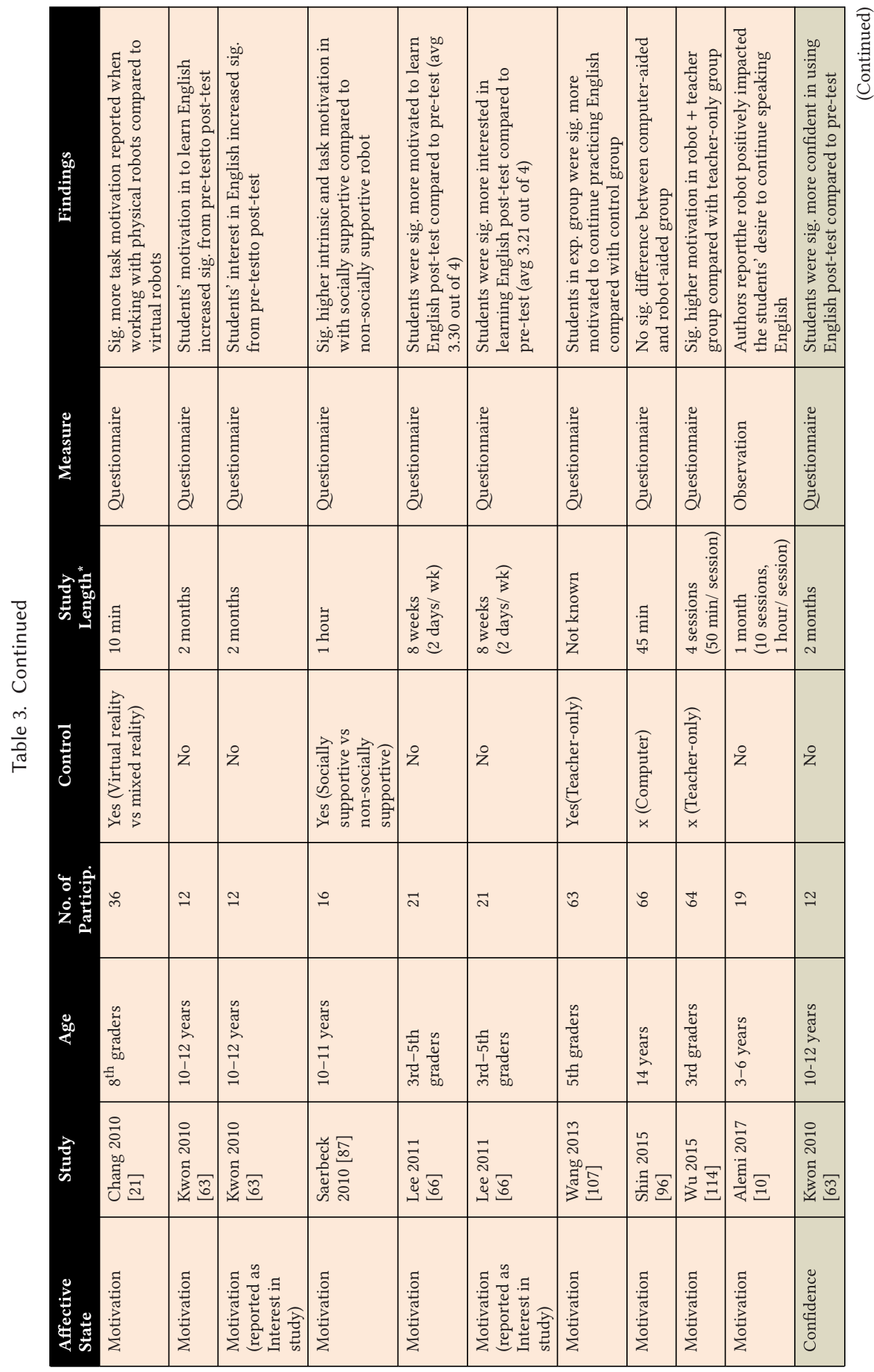




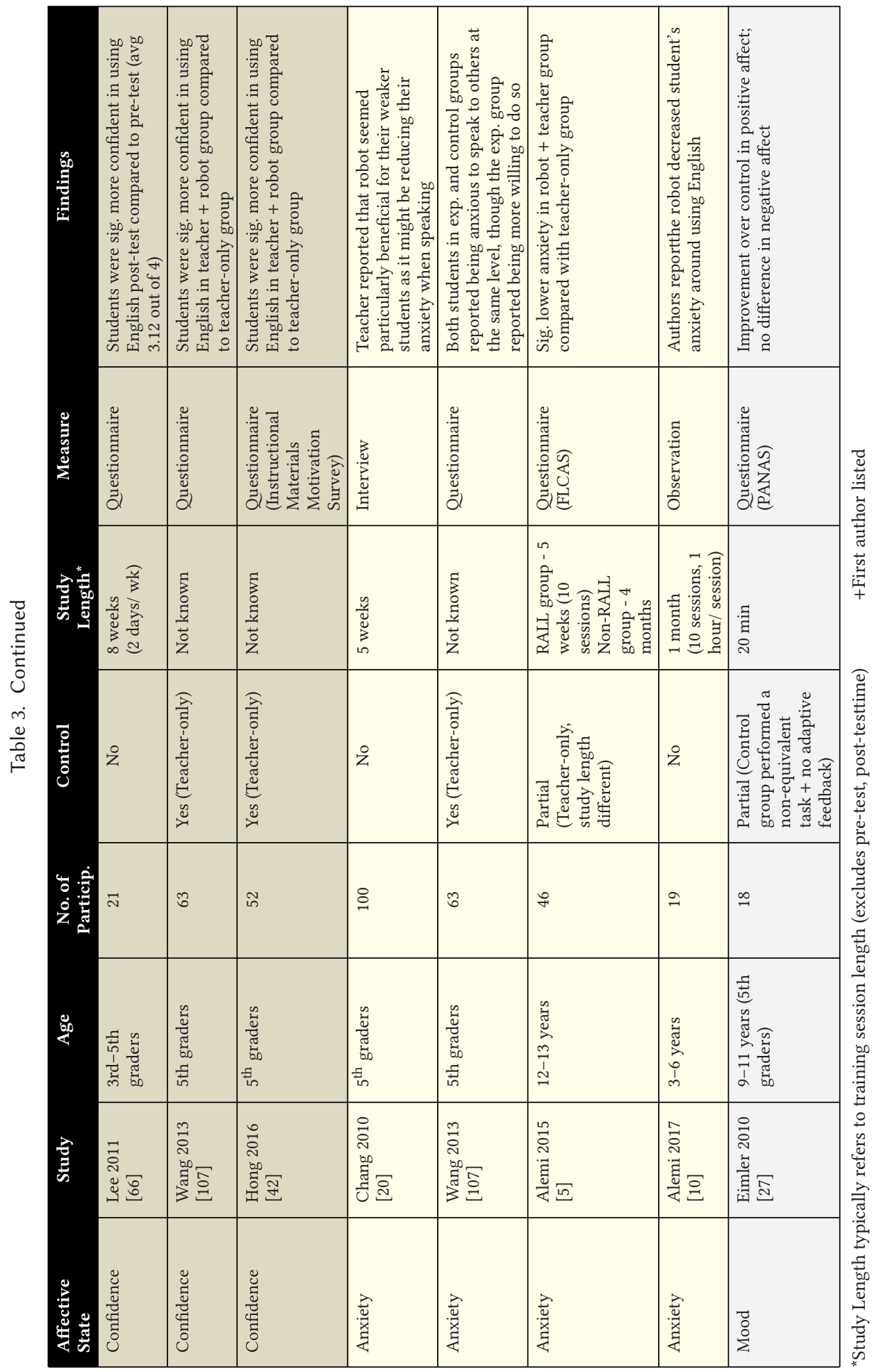




\section{REFERENCES}

[1] Olusola O. Adesope, Tracy Lavin, Terri Thompson, and Charles Ungerleider. 2010. A systematic review and metaanalysis of the cognitive correlates of bilingualism. Rev. Ed. Res. 80, 2 (2010), 207-245.

[2] Tracy McKee Agostin and Sherry K. Bain. 1997. Predicting early school success with developmental and social skills screeners. Psych. Schools 34, 3 (1997), 219-228.

[3] Neziha Akalin, Pinar Uluer, and Hatice Kose. 2013. Ispy-usign humanoid assisted interactive sign language tutoring games. In Proceedings of the IEEE International Symposium on Robot and Human Interactive Communication (ROMAN'13). 290-291. Retrieved from http://ieeexplore.ieee.org/xpls/abs_all.jsp?arnumber $=6628428$.

[4] Neziha Akalin, Pinar Uluer, and Hatice Kose. 2014. Non-verbal communication with a social robot peer: Towards robot assisted interactive sign language tutoring. In Proceedings of the IEEE-RAS International Conference on Humanoid Robots. 1122-1127. Retrieved from http://ieeexplore.ieee.org/xpls/abs_all.jsp?arnumber=7041509.

[5] M. Alemi, A. Meghdari, and M. Ghazisaedy. 2015. The impact of social robotics on L2 learners' anxiety and attitude in English vocabulary acquisition. Int. F. Soc. Rob. 7, 4 (2015), 523-535.

[6] Minoo Alemi and Nasim Mahboub Basirib. 2016. Exploring social robots as a tool for special education to teach english to iranian kids with autism. Int. F. Rob., Theor. Appl. 4, 4 (2016), 32-43.

[7] Minoo Alemi, Ali Meghdari, Nasim Mahboub Basiri, and Alireza Taheri. 2015. The effect of applying humanoid robots as teacher assistants to help Iranian autistic pupils learn English as a foreign language. In Proceedings of the International Conference on Social Robotics. 1-10. Retrieved from http://link.springer.com/chapter/10.1007/ 978-3-319-25554-5_1.

[8] Minoo Alemi, Ali Meghdari, and Maryam Ghazisaedy. 2014. Employing humanoid robots for teaching English language in Iranian junior high schools. Int. J. Humanoid Rob. 11, 31450022.

[9] Minoo Alemi, Ali Meghdari, and Maryam Ghazisaedy. 2014. The effect of employing humanoid robots for teaching English on students' anxiety and attitude. In Proceedings of the 2nd RSI/ISM International Conference on Robotics and Mechatronics (ICRoM'14). 754-759. Retrieved from: http://ieeexplore.ieee.org/xpls/abs_all.jsp?arnumber=6990994.

[10] Minoo Alemi, Ali Meghdari, and Nafiseh Sadat Haeri. 2017. Young EFL learners' attitude towards RALL: An observational study focusing on motivation, anxiety, and interaction. In Proceedings of the International Conference on Social Robotics. 252-261.

[11] Ilhan Bae and Jeonghye Han. 2017. Does height affect the strictness of robot assisted teacher? In Proceedings of the Companion of the ACM/IEEE International Conference on Human-Robot Interaction. 73-74.

[12] Thomas H. Bak, Jack J. Nissan, Michael M. Allerhand, and Ian J. Deary. 2014. Does bilingualism influence cognitive aging? Ann. Neurology 75, 6 (2014), 959-963.

[13] Kairat Balkibekov, Serik Meiirbekov, Nazgul Tazhigaliyeva, and Anara Sandygulova. 2016. Should robots win or lose? Robot's losing playing strategy positively affects child learning. In Proceedings of the 25th IEEE International Symposium on Robot and Human Interactive Communication (RO-MAN'16). 706-711.

[14] Tony Belpaeme, James Kennedy, Aditi Ramachandran, Brian Scassellati, and Fumihide Tanaka. 2018. Social robots for education: A review. Sci. Rob. 3, 21 (15 Aug. 2018), eaat5954.

[15] Ellen Bialystok, Fergus I. M. Craik, and Morris Freedman. 2007. Bilingualism as a protection against the onset of symptoms of dementia. Neuropsychologia 45, 2 (2007), 459-464.

[16] David Birdsong. 1999. Second Language Acquisition and the Critical Period Hypothesis. Routledge.

[17] Benjamin S. Bloom. 1984. The 2 sigma problem: The search for methods of group instruction as effective as one-toone tutoring. Ed. Res. 13, 6 (1984), 4-16.

[18] Holly P. Branigan, Martin J. Pickering, Jamie Pearson, and Janet F. McLean. 2010. Linguistic alignment between people and computers. F. Prag. 42, 9 (2010), 2355-2368.

[19] Marianne Celce-Murcia. 2001. Language teaching approaches: An overview. Teaching English as a Second or Foreign Language, Vol. 2 Heinle \& Heinle Publishers, Boston, Massachusetts, 3-10.

[20] Chih-Wei Chang, Jih-Hsien Lee, Po-Yao Chao, Chin-Yeh Wang, Gwo-Dong Chen, et al. 2010. Exploring the possibility of using humanoid robots as instructional tools for teaching a second language in primary school. Ed. Technol. Soc. 13, 2 (2010), 13-24.

[21] Chih-Wei Chang, Jih-Hsien Lee, Chin-Yeh Wang, and Gwo-Dong Chen. 2010. Improving the authentic learning experience by integrating robots into the mixed-reality environment. Comput. Ed. 55, 4 (2010), 1572-1578.

[22] Gwo-Dong Chen and Chih-Wei Chang. 2009. A task-based role-playing game with educational robots for learning language. In Proceedings of the International Conference on Technologies for E-Learning and Digital Entertainment, 483-488. Retrieved from http://link.springer.com/chapter/10.1007/978-3-642-03364-3_58.

[23] Nian-Shing Chen, Benazir Quadir, and Daniel C. Teng. 2011. Integrating book, digital content and robot for enhancing elementary school students' learning of English. Austral. f. Ed. Technol. 27, 3. Retrieved from http: //ascilite.org.au/ajet/submission/index.php/AJET/article/view/960. 
[24] Joost van Doremalen, Lou Boves, Jozef Colpaert, Catia Cucchiarini, and Helmer Strik. 2016. Evaluating automatic speech recognition-based language learning systems: A case study. Comput. Assist. Lang. Learn. 29, 4 (2016), 833-851.

[25] Zoltán Dörnyei. 1998. Motivation in second and foreign language learning. Lang. Teach. 31, 3 (1998), 117-135.

[26] Greg J. Duncan, Chantelle J. Dowsett, Amy Claessens, Katherine Magnuson, Aletha C. Huston, Pamela Klebanov, Linda S. Pagani, Leon Feinstein, Mimi Engel, and Jeanne Brooks-Gunn. 2007. School readiness and later achievement. Dev. Psych. 43, 6 (2007), 1428.

[27] Sabrina Eimler, Astrid von der Pütten, Ulrich Schächtle, Lucas Carstens, and Nicole Krämer. 2010. Following the white rabbit-A robot rabbit as vocabulary trainer for beginners of English. In Proceedings of the Symposium of the Austrian HCI and Usability Engineering Group. 322-339. Retrieved from http://link.springer.com/chapter/10.1007/ 978-3-642-16607-5_22.

[28] Rod Ellis. 2003. Task-based Language Learning and Teaching. Oxford University Press.

[29] Bekir Sitkı Ertuğrul, Cemal Gurpinar, Hasan Kivrak, and Hatice Kose. 2013. Gesture recognition for humanoid assisted interactive sign language tutoring. In Proceedings of the $21^{\text {st }}$ Signal Processing and Communications Applications Conference (SIU'13). 1-4. Retrieved from http://ieeexplore.ieee.org/xpls/abs_all.jsp?arnumber=6531542.

[30] Matteo Gerosa, Diego Giuliani, Shrikanth Narayanan, and Alexandros Potamianos. 2009. A review of ASR technologies for children's speech. In Proceedings of the 2nd Workshop on Child, Computer and Interaction, 7.

[31] Goren Gordon and Cynthia Breazeal. 2015. Bayesian active learning-based robot tutor for children's word-reading skills. In Proceedings of the AAAI Conference on Artificial Intelligence (AAAI'15). 1343-1349. Retrieved from http:// robotshelpingkids.yale.edu/sites/default/files/files/GordonBreazeal_AAAI_2015_final.pdf.

[32] Goren Gordon, Cynthia Breazeal, and Susan Engel. 2015. Can children catch curiosity from a social robot? In Proceedings of the 10th ACM/IEEE International Conference on Human-Robot Interaction. 91-98. Retrieved from http:// dl.acm.org/citation.cfm?id=2696469.

[33] Goren Gordon, Samuel Spaulding, Jacqueline Kory Westlund, Jin Joo Lee, Luke Plummer, Marayna Martinez, Madhurima Das, and Cynthia Breazeal. 2016. Affective personalization of a social robot tutor for children's second language skills. In Proceedings of the 30th AAAI Conference on Artificial Intelligence. Retrieved from http: //www.aaai.org/ocs/index.php/AAAI/AAAI16/paper/view/11759.

[34] Joan Gorham. 1988. The relationship between verbal teacher immediacy behaviors and student learning. Commun. Ed. 37, 1 (1988), 40-53.

[35] Juho Hamari, Jonna Koivisto, and Harri Sarsa. 2014. Does gamification work? A literature review of empirical studies on gamification. In Proceedings of the Hawaii International Conference on System Sciences (HICSS'14). 3025-3034.

[36] Jeonghye Han. 2012. Emerging technologies: Robot assisted language learning. Lang. Learn. Technol. 16, 3 (2012), $1-9$.

[37] Jeong-Hye Han, Mi-Heon Jo, Vicki Jones, and Jun-H. Jo. 2008. Comparative study on the educational use of home robots for children. J. Inf. Proc. Syst. 4, 4 (2008), 159-168.

[38] Jeonghye Han and Dongho Kim. 2009. r-Learning services for elementary school students with a teaching assistant robot. In Proceedings of the 4th ACM/IEEE International Conference on Human-Robot Interaction (HRI'09). 255-256. Retrieved from http://ieeexplore.ieee.org/xpls/abs_all.jsp?arnumber=6256051.

[39] J. Hemminki and A. Erkinheimo-Kyllönen. 2017. A humanoid robot as a language tutor. In Proceedings of R4L@ HRI2017.

[40] James M. Hendrickson. 1992. Storytelling for Foreign Language Learners.

[41] Jonathan S. Herberg, Sebastian Feller, Ilker Yengin, and Martin Saerbeck. 2015. Robot watchfulness hinders learning performance. In Proceedings of the 24th IEEE International Symposium on Robot and Human Interactive Communication (RO-MAN'15). 153-160. Retrieved from http://ieeexplore.ieee.org/xpls/abs_all.jsp?arnumber=7333620.

[42] Zeng-Wei Hong, Yueh-Min Huang, Marie Hsu, and Wei-Wei Shen. 2016. Authoring robot-assisted instructional materials for improving learning performance and motivation in EFL classrooms. F. Edu. Technol. Soc. 19, 1 (2016), 337-349.

[43] YunYoung Hur and Jeonghye Han. 2009. Analysis on children's tolerance to weak recognition of storytelling robots. f. Converg. Inf. Technol. 4, 3 (2009), 103-109.

[44] Eun-ja Hyun, So-yeon Kim, Siekyung Jang, and Sungju Park. 2008. Comparative study of effects of language instruction program using intelligence robot and multimedia on linguistic ability of young children. In Proceedings of the 17th IEEE International Symposium on Robot and Human Interactive Communication (RO-MAN'08). 187-192. Retrieved from http://ieeexplore.ieee.org/xpls/abs_all.jsp?arnumber=4600664.

[45] Jiyoung In and Jeonghye Han. 2015. The acoustic-phonetics change of English learners in robot assisted learning. In Proceedings of the 10th ACM/IEEE International Conference on Human-Robot Interaction Extended Abstracts. 39-40.

[46] Mitsuru Ishida, AlBara Khalifa, Tsuneo Kato, and Seiichi Yamamoto. 2016. Features of learner corpus collected with joining-in type robot assisted language learning system. In Proceedings of the Conference of the Oriental Chapter 
of International Committee for Coordination and Standardization of Speech Databases and Assessment Techniques (O-COCOSDA'16). 128-131.

[47] Alexis D. Jacq, Séverin Lemaignan, Fernando Garcia, Pierre Dillenbourg, and Ana Paiva. 2016. Building successful long child-robot interactions in a learning context. In Proceedings of the 11th ACM/IEEE International Conference on Human Robot Interaction. 239-246.

[48] Jacqueline S. Johnson and Elissa L. Newport. 1989. Critical period effects in second language learning: The influence of maturational state on the acquisition of English as a second language. Cog. Psych. 21, 1 (1989), 60-99.

[49] Younbo Jung and Kwan Min Lee. 2004. Effects of physical embodiment on social presence of social robots. Proc. PRESENCE: 80-87.

[50] Takayuki Kanda, Takayuki Hirano, Daniel Eaton, and Hiroshi Ishiguro. 2004. Interactive robots as social partners and peer tutors for children: A field trial. Hum.-Comput. Int. 19, 1 (2004), 61-84.

[51] Takayuki Kanda, Rumi Sato, Naoki Saiwaki, and Hiroshi Ishiguro. 2007. A two-month field trial in an elementary school for long-term human-robot interaction. IEEE Trans. Rob. 23, 5 (2007), 962-971.

[52] Junko Kanero, Vasfiye Geçkin, Cansu Oranç, Ezgi Mamus, Aylin C. Küntay, and Tilbe Göksun. 2018. Social robots for early language learning: Current evidence and future directions. Child Dev. Persp.

[53] James Kennedy, Paul Baxter, Emmanuel Senft, and Tony Belpaeme. 2015. Higher nonverbal immediacy leads to greater learning gains in child-robot tutoring interactions. In Proceedings of the International Conference on Social Robotics. 327-336.

[54] James Kennedy, Paul Baxter, Emmanuel Senft, and Tony Belpaeme. 2016. Social robot tutoring for child second language learning. In Proceedings of the 11th ACM/IEEE International Conference on Human-Robot Interaction (HRI'16). 231-238. Retrieved from http://ieeexplore.ieee.org/xpls/abs_all.jsp?arnumber $=7451757$.

[55] James Kennedy, Séverin Lemaignan, Caroline Montassier, Pauline Lavalade, Bahar Irfan, Fotios Papadopoulos, Emmanuel Senft, and Tony Belpaeme. 2017. Child speech recognition in human-robot interaction: Evaluations and recommendations. In Proceedings of the ACM/IEEE International Conference on Human-Robot Interaction. 82-90.

[56] AlBara Khalifa, Tsuneo Kato, and Seiichi Yamamoto. 2017. Measuring effect of repetitive queries and implicit learning with joining-in type robot assisted language learning system. In Proceedings of the 7th ISCA Workshop on Speech and Language Technology in Education. 13-17.

[57] Yanghee Kim, Diantha Smith, Namju Kim, and Tianyu Chen. 2014. Playing with a robot to learn English vocabulary. In Proceedings of the KAERA Research Forum. Retrieved from https://works.bepress.com/yanghee_kim/59/.

[58] Jacqueline Kory and Cynthia Breazeal. 2014. Storytelling with robots: Learning companions for preschool children's language development. In Proceedings of the 23rd IEEE International Symposium on Robot and Human Interactive Communication. 643-648. Retrieved from http://ieeexplore.ieee.org/xpls/abs_all.jsp?arnumber=6926325.

[59] Hatice Kose, Neziha Akalin, and Pinar Uluer. 2014. Socially interactive robotic platforms as sign language tutors. Int. f. Humanoid Rob. 11, 01: 1450003.

[60] Hatice Köse, Pınar Uluer, Neziha Akalın, Rabia Yorganc1, Ahmet Özkul, and Gökhan Ince. 2015. The effect of embodiment in sign language tutoring with assistive humanoid robots. Int. F. Soc. Rob. 7, 4 (2015), 537-548.

[61] Hatice Kose and Rabia Yorganci. 2011. Tale of a robot: Humanoid robot assisted sign language tutoring. In Proceedings of the 11th IEEE-RAS International Conference on Humanoid Robots (Humanoids'11). 105-111. Retrieved from http:// ieeexplore.ieee.org/xpls/abs_all.jsp?arnumber=6100846.

[62] Hatice Kose, Rabia Yorganci, Esra H. Algan, and Dag S. Syrdal. 2012. Evaluation of the robot assisted sign language tutoring using video-based studies. Int. F. Soc. Rob. 4, 3 (2012), 273-283.

[63] Oh-Hun Kwon, Seong-Yong Koo, Young-Geun Kim, and Dong-Soo Kwon. 2010. Telepresence robot system for English tutoring. In Proceedings of the IEEE Workshop on Advanced Robotics and Its Social Impacts. 152-155. Retrieved from http://ieeexplore.ieee.org/xpls/abs_all.jsp?arnumber=5679999.

[64] Hawon Lee and Eunja Hyun. 2015. The intelligent robot contents for children with speech-language disorder. F. Ed. Technol. Soc. 18, 3 (2015), 100.

[65] Sungjin Lee, Changgu Kim, Jonghoon Lee, Hyungjong Noh, Kyusong Lee, and Gary Geunbae Lee. 2010. Affective effects of speech-enabled robots for language learning. In Proceedings of the Spoken Language Technology Workshop (SLT'10). IEEE, 145-150. Retrieved from http://ieeexplore.ieee.org/xpls/abs_all.jsp?arnumber=5700837.

[66] Sungjin Lee, Hyungjong Noh, Jonghoon Lee, Kyusong Lee, Gary Geunbae Lee, Seongdae Sagong, and Munsang Kim. 2011. On the effectiveness of robot-assisted language learning. ReCALL 23, 1: 25-58.

[67] Daniel Leyzberg, Samuel Spaulding, and Brian Scassellati. 2014. Personalizing robot tutors to individuals' learning differences. In Proceedings of the ACM/IEEE International Conference on Human-Robot Interaction. 423-430.

[68] Grace Hui Chin Lin. 2008. Pedagogies proving Krashen's theory of affective filter. Hwa Kang Journal of English Language \& Literature 14 (2008), 113-131.

[69] José Lopes, Olov Engwall, and Gabriel Skantze. 2017. A first visit to the robot language café. In Proceedings of the 7th ISCA Workshop on Speech and Language Technology in Education. 7-12. 
[70] Ying-Tsuan Lu, Chih-Wei Chang, and Gwo-Dong Chen. 2007. Using a programmable storytelling robot to motivate learning second language. In Proceedings of the 7th IEEE International Conference on Advanced Learning Technologies (ICALT'07). 841-844. Retrieved from http://ieeexplore.ieee.org/xpls/abs_all.jsp?arnumber=4281172.

[71] Elvis Mazzoni and Martina Benvenuti. 2015. A robot-partner for preschool children learning English using sociocognitive conflict. Edu. Technol. Soc. 18, 4 (2015), 474-485.

[72] Javier Movellan, Micah Eckhardt, Marjo Virnes, and Angelica Rodriguez. 2009. Sociable robot improves toddler vocabulary skills. In Proceedings of the 4th ACM/IEEE International Conference on Human Robot Interaction. 307-308. Retrieved from http://dl.acm.org/citation.cfm?id=1514189.

[73] Omar Mubin, Suleman Shahid, and Christoph Bartneck. 2013. Robot assisted language learning through games: A comparison of two case studies. Retrieved from http://ir.canterbury.ac.nz/handle/10092/9198.

[74] Ryo Nagata, Tomoya Mizumoto, Kotaro Funakoshi, and Mikio Nakano. 2010. Toward a chanting robot for interactively teaching English to children. In Proceedings of the INTERSPEECH Satellite Workshop on Second Language Studies: Acquisition, Learning, Education and Technology, P2-13. Retrieved from http://www.gavo.t.u-tokyo.ac.jp/ L2WS2010/papers/L2WS2010_P2-13.pdf.

[75] Norbahira Mohamad Nor and Radzuwan Ab Rashid. 2018. A review of theoretical perspectives on language learning and acquisition. Kasetsart f. Soc. Sci. 39, 1 (2018), 161-167.

[76] Junichi Osada, Shinichi Ohnaka, and Miki Sato. 2006. The scenario and design process of childcare robot, PaPeRo. In Proceedings of the ACM SIGCHI International Conference on Advances in Computer Entertainment Technology. 80. Retrieved from http://dl.acm.org/citation.cfm?id=1178917.

[77] Sharon Oviatt, Courtney Darves, and Rachel Coulston. 2004. Toward adaptive conversational interfaces: Modeling speech convergence with animated personas. ACM Trans. Comput.-Hum. Interact. 11, 3 (2004), 300-328.

[78] Rebecca Oxford and Jill Shearin. 1994. Language learning motivation: Expanding the theoretical framework. Mod. Lang. 7. 78, 1 (1994), 12-28.

[79] Barbara C. Palmer, Shelley J. Harshbarger, and Cindy A. Koch. 2001. Storytelling as a constructivist model for developing language and literacy. f. Poetry Ther. 14, 4 (2001), 199-212.

[80] Seong Ju Park, Jeong Hye Han, Bok Hyun Kang, and Kyung Chul Shin. 2011. Teaching assistant robot, ROBOSEM, in English class and practical issues for its diffusion. In Proceedings of the IEEE Workshop on Advanced Robotics and Its Social Impacts (ARSO'11). 8-11. Retrieved from http://ieeexplore.ieee.org/xpls/abs_all.jsp?arnumber=6301971.

[81] Leah Perlmutter, Alexander Fiannaca, Eric Kernfeld, Sahil Anand, Lindsey Arnold, and Maya Cakmak. 2016. Automatic adaptation of online language lessons for robot tutoring. In Proceedings of the International Conference on Social Robotics. 660-670. Retrieved from http://link.springer.com/chapter/10.1007/978-3-319-47437-3_65.

[82] Harshalata Petkar. 2016. A review of challenges in automatic speech recognition. Int. f. Comput. Appl. 151, 3.

[83] Alexandros Potamianos and Shrikanth Narayanan. 2003. Robust recognition of children's speech. IEEE Trans. Speech Audio Proc. 11, 6 (2003), 603-616.

[84] Jack C. Richards and Ted Rodgers. 1982. Method: Approach, design, and procedure. Tesol Quarterly 16, 2 (1982), 153-168.

[85] Astrid M. Rosenthal-von der Pütten, Carolin Strassmann, and Nicole C. Krämer. 2016. Robots or agents-neither helps you more or less during second language acquisition. In Proceedings of the International Conference on Intelligent Virtual Agents. 256-268.

[86] Kimiko Ryokai, Cati Vaucelle, and Justine Cassell. 2003. Virtual peers as partners in storytelling and literacy learning. f. Comput. Assist. Learn. 19, 2 (2003), 195-208.

[87] Martin Saerbeck, Tom Schut, Christoph Bartneck, and Maddy D. Janse. 2010. Expressive robots in education: Varying the degree of social supportive behavior of a robotic tutor. In Proceedings of the SIGCHI Conference on Human Factors in Computing Systems. 1613-1622. Retrieved from http://dl.acm.org/citation.cfm?id=1753567.

[88] Albert Saiz and Elena Zoido. 2006. Listening to what the world says: Bilingualism and earnings in the United States. Listening 87, 3.

[89] Sandra Sampayo-Vargas, Chris J. Cope, Zhen He, and Graeme J. Byrne. 2013. The effectiveness of adaptive difficulty adjustments on students' motivation and learning in an educational computer game. Comput. Ed. 69 (2013) 452-462.

[90] Sandra J. Savignon. 1991. Communicative language teaching: State of the art. TESOL Quarterly 25, 2 (1991) 261-278

[91] Thorsten Schodde, Kirsten Bergmann, and Stefan Kopp. 2017. Adaptive robot language tutoring based on Bayesian knowledge tracing and predictive decision-making. In Proceedings of the ACM/IEEE International Conference on Human-Robot Interaction. 128-136.

[92] Thorsten Schodde, Laura Hoffmann, and Stefan Kopp. 2017. How to manage affective state in child-robot tutoring interactions? In International Conference on Companion Technology (ICCT'17). IEEE, 1-6.

[93] Younghee Sheen. 2008. Recasts, language anxiety, modified output, and L2 learning. Lang. Learn. 58, 4 (2008) 835874. 
[94] Chao-Fen Shih, Chih-Wei Chang, and Gwo-Dong Chen. 2007. Robot as a storytelling partner in the English classroom-preliminary discussion. In Proceedings of the 7th IEEE International Conference on Advanced Learning Technologies (ICALT'07). 678-682. Retrieved from http://ieeexplore.ieee.org/xpls/abs_all.jsp?arnumber=4281125.

[95] KyuNam Shim, Deok-Gi Min, and Seungmin Lee. 2012. A model of robot-assisted assessment of primary school students' English speaking. Education 18, 3 (2012), 399-417.

[96] Jae-eun Shin and Dong-Hee Shin. 2015. Robot as a facilitator in language conversation class. In Proceedings of the 10th ACM/IEEE International Conference on Human-Robot Interaction Extended Abstracts. 11-12. Retrieved from http:// dl.acm.org/citation.cfm?id=2702062.

[97] Kyoung Wan Cathy Shin and Jeong-Hye Han. 2017. Qualitative exploration on children's interactions in telepresence robot assisted language learning. 한국융합학회논문지 8, 3 (2017), 177-184.

[98] Prashanth Gurunath Shivakumar and Panayiotis Georgiou. 2018. Transfer learning from adult to children for speech recognition: Evaluation, analysis and recommendations. Arxiv Preprint ArXiv:1805.03322.

[99] Fumihide Tanaka and Shizuko Matsuzoe. 2012. Children teach a care-receiving robot to promote their learning: Field experiments in a classroom for vocabulary learning. f. Hum.-Rob. Interact. 1, 1. Retrieved from http://hri-journal. org/index.php/HRI/article/view/12.

[100] Fumihide Tanaka, Toshimitsu Takahashi, Shizuko Matsuzoe, Nao Tazawa, and Masahiko Morita. 2013. Childoperated telepresence robot: A field trial connecting classrooms between Australia and Japan. In Proceedings of the IEEE/RSf International Conference on Intelligent Robots and Systems. 5896-5901. Retrieved from http://ieeexplore. ieee.org/xpls/abs_all.jsp?arnumber=6697211.

[101] Pınar Uluer, Neziha Akalın, and Hatice Köse. 2015. A new robotic platform for sign language tutoring. Int. F. Soc. Rob. 7, 5 (2015), 571-585.

[102] Paul Vogt, Sherily Dunk, and Paul Poos. 2017. Foreign language tutoring for young adults with severe learning problems. In Proceedings of the ACM/IEEE International Conference on Human-Robot Interaction. 317-318.

[103] Paul Vogt, Mirjam de Haas, Chiara de Jong, Peta Baxter, and Emiel Krahmer. 2017. Child-robot interactions for second language tutoring to preschool children. Front. Hum. Neurosci. 11 (2017), 73.

[104] Joshua Wainer, David J. Feil-Seifer, Dylan A. Shell, and Maja J. Mataric. 2007. Embodiment and human-robot interaction: A task-based perspective. In Proceedings of the 16th IEEE International Symposium on Robot and Human Interactive Communication (RO-MAN'07). 872-877.

[105] Dale Walker, Charles Greenwood, Betty Hart, and Judith Carta. 1994. Prediction of school outcomes based on early language production and socioeconomic factors. Child Dev. 65, 2 (1994), 606-621.

[106] Yi Hsuan Wang, Shelley S. C. Young, and Jyh-Shing Roger Jang. 2009. Evaluation of tangible learning companion/robot for English language learning. In Proceedings of the 9th IEEE International Conference on Advanced Learning Technologies. 322-326. Retrieved from http://ieeexplore.ieee.org/xpls/abs_all.jsp?arnumber $=5194239$.

[107] Yi Hsuan Wang, Shelley Shwu-Ching Young, and Jyh-Shing Roger Jang. 2013. Using tangible companions for enhancing learning English conversation. Edu. Technol. Soc. 16, 2 (2013), 296-309.

[108] Andreas Wedenborn. 2015. A Physical Robot's Effect on Vocabulary Learning. DiVA.

[109] Westlund and Cynthia Breazeal. 2015. The interplay of robot language level with children's language learning during storytelling. In Proceedings of the 10th ACM/IEEE International Conference on Human-Robot Interaction, Extended Abstracts. 65-66. Retrieved from http://dl.acm.org/citation.cfm?id=2701989.

[110] J. Kory Westlund, Leah Dickens, Sooyeon Jeong, Paul Harris, David DeSteno, and Cynthia Breazeal. 2015. A comparison of children learning new words from robots, tablets, and people. In Proceedings of the Conference Proceedings New Friends 2015. Retrieved from http://newfriends2015.org/Proceedings/Contents/Papers/New_Friends_2015_ submission_18.pdf.

[111] J. Kory Westlund, Goren Gordon, Samuel Spaulding, Jin Joo Lee, Luke Plummer, Marayna Martinez, Madhurima Das, and Cynthia Breazeal. 2015. Learning a second language with a socially assistive robot. In The 1st International Conference on Social Robots in Therapy and Education. Almere, The Netherlands. Retrieved from http://doc.utwente. nl/99208/1/ProceedingsNF20154.pdf\#page=32.

[112] Jacqueline M. Kory Westlund, Leah Dickens, Sooyeon Jeong, Paul L. Harris, David DeSteno, and Cynthia L. Breazeal. 2017. Children use non-verbal cues to learn new words from robots as well as people. Int. f. Child-Comput. Interact. Retrieved from http://www.sciencedirect.com/science/article/pii/S2212868916300538.

[113] Paul L. Witt, Lawrence R. Wheeless, and Mike Allen. 2004. A meta-analytical review of the relationship between teacher immediacy and student learning. Commun. Monogr. 71, 2 (2004), 184-207.

[114] Wen-Chi Vivian Wu, Rong-Jyue Wang, and Nian-Shing Chen. 2015. Instructional design using an in-house built teaching assistant robot to enhance elementary school English-as-a-foreign-language learning. Interact. Learn. Environ. 23, 6 (2015), 696-714. 
[115] Akihiro Yorita, Janos Botzheim, and Naoyuki Kubota. 2013. Self-efficacy using fuzzy control for long-term communication in robot-assisted language learning. In Proceedings of the IEEE/RSF International Conference on Intelligent Robots and Systems. 5708-5715. Retrieved from http://ieeexplore.ieee.org/xpls/abs_all.jsp?arnumber=6697183.

[116] Akihiro Yorita and Naoyuki Kubota. 2012. Mutual learning for second language education and language acquisition of robots. In Advances in Autonomous Mini Robots. Springer, 75-87. Retrieved from http://link.springer.com/chapter/ 10.1007/978-3-642-27482-4_10.

[117] Zhen-Jia You, Chi-Yuh Shen, Chih-Wei Chang, Baw-Jhiune Liu, and Gwo-Dong Chen. 2006. A robot as a teaching assistant in an English class. In Proceedings of the 6th IEEE International Conference on Advanced Learning Technologies (ICALT'06), 87-91. Retrieved from http://ieeexplore.ieee.org/xpls/abs_all.jsp?arnumber=1652373.

[118] Shelley Shwu-Ching Young, Yi Hsuan Wang, and Jyh-Shing Roger Jang. 2010. Exploring perceptions of integrating tangible learning companions in learning English conversation. British f. Edu. Technol. 41, 5 (2010), E78-E83.

[119] Sangseok Yun, Jongju Shin, Daijin Kim, Chang Gu Kim, Munsang Kim, and Mun-Taek Choi. 2011. Engkey: Teleeducation robot. In Proceedings of the International Conference on Social Robotics, 142-152. Retrieved from http: //link.springer.com/chapter/10.1007/978-3-642-25504-5_15.

[120] Mohammad Zakipour, Ali Meghdari, and Minoo Alemi. 2016. RASA: A low-cost upper-torso social robot acting as a sign language teaching assistant. In Proceedings of the International Conference on Social Robotics. 630-639. Retrieved from http://link.springer.com/chapter/10.1007/978-3-319-47437-3_62.

[121] Figure 1.2 http://www.bartneck.de/2009/08/12/photos-of-philips-icat-robot/. Christopher Bartneck. 5/9/2019.

[122] Figure 1.3. https://spectrum.ieee.org/automaton/robotics/artificial-intelligence/mit-dragonbot-evolving-to-betterteach-kids. Polly Guggenheim. 5/9/2019.

Received June 2018; revised May 2019; accepted July 2019 